ARTICLE

https://doi.org/10.1038/s41467-018-07815-5

\title{
Broad CD8 + T cell cross-recognition of distinct influenza A strains in humans
}

\author{
Emma J. Grant ${ }^{1,2}$, Tracy M. Josephs², Liyen Loh¹, E. Bridie Clemens', Sneha Sant ${ }^{1}$, Mandvi Bharadwaj ${ }^{1}$, \\ Weisan Chen ${ }^{3}$, Jamie Rossjohn (10 2,4,5, Stephanie Gras ${ }^{2,5}$ \& Katherine Kedzierska ${ }^{1}$
}

Newly-emerged and vaccine-mismatched influenza A viruses (IAVs) result in a rapid global spread of the virus due to minimal antibody-mediated immunity. In that case, established $\mathrm{CD}^{+}{ }^{+} \mathrm{T}$-cells can reduce disease severity. However, as mutations occur sporadically within immunogenic IAV-derived T-cell peptides, understanding of T-cell receptor (TCR $\alpha \beta$ ) crossreactivity towards IAV variants is needed for a vaccine design. Here, we investigate TCR $\alpha \beta$ cross-strain recognition across IAV variants within two immunodominant human IAVspecific CD8 ${ }^{+}$T-cell epitopes, HLA-B*37:01-restricted $\mathrm{NP}_{338-346}\left(\mathrm{~B}_{\left.37-\mathrm{NP}_{338}\right)}\right.$ ) and HLA$A^{\star} 01: 01-r e s t r i c t e d N_{44-52}\left(A 1-N P_{44}\right)$. We find high abundance of cross-reactive $T C R \alpha \beta$ clonotypes recognizing distinct IAV variants. Structures of the wild-type and variant peptides revealed preserved conformation of the bound peptides. Structures of a cross-reactive TCRHLA-B37-NP 338 complex suggest that the conserved conformation of the variants underpins TCR cross-reactivity. Overall, cross-reactive $\mathrm{CD} 8^{+} \mathrm{T}$-cell responses, underpinned by conserved epitope structure, facilitates recognition of distinct IAV variants, thus CD8 ${ }^{+} \mathrm{T}$-celltargeted vaccines could provide protection across different IAV strains.

\footnotetext{
${ }^{1}$ Department of Microbiology and Immunology, The University of Melbourne, at the Peter Doherty Institute for Infection and Immunity, Melbourne, VIC 3010 Australia. ${ }^{2}$ Infection and Immunity Program and Department of Biochemistry and Molecular Biology, Biomedicine Discovery Institute, Monash University, Clayton, VIC 3800, Australia. ${ }^{3}$ Department of Biochemistry and Genetics, La Trobe Institute of Molecular Science, La Trobe University, Bundoora 3084 VIC, Australia. ${ }^{4}$ Institute of Infection and Immunity, School of Medicine, Cardiff University, Cardiff CF14 4XN, UK. ${ }^{5}$ ARC Centre of Excellence in Advanced Molecular Imaging, Monash University, Clayton, VIC 3800, Australia. These authors contributed equally: Stephanie Gras, Katherine Kedzierska. Correspondence and requests for materials should be addressed to S.G. (email: stephanie.gras@monash.edu) or to K.K. (email: kkedz@unimelb.edu.au)
} 
nfluenza A viruses (IAVs) rapidly evolve and cause significant morbidity and mortality (reviewed in refs. ${ }^{1,2}$ ). Annual epi-

demics are responsible for $>500,000$ deaths worldwide ${ }^{3}$, while pandemics can cause $>50$ million deaths (reviewed in ref. ${ }^{4}$ ). Although vaccines are available, they primarily induce neutralizing antibodies directed towards the rapidly mutating surface glycoproteins, rather than cross-reactive $\mathrm{CD}^{+} \mathrm{T}$ cell immunity 1,5 , mandating that these vaccines are updated and administered annually (reviewed in ref. ${ }^{6}$ ). Furthermore, these vaccines are fallible when the circulating strains do not match the predicted vaccine strains ${ }^{7}$ or in a scenario when a novel viral subtype enters the population. Thus there is an urgent need to understand correlates of $\mathrm{T}$ cell protection towards IAV to provide effective influenza vaccine design.

In the absence of neutralizing antibodies, strain cross-reactive $\mathrm{CD}^{+} \mathrm{T}$ cells can protect against IAVs. Murine studies show that $\mathrm{CD}^{+} \mathrm{T}$ cells correlate with decreased morbidity and mortality following IAV infection ${ }^{8-12}$ and can provide protection during infection with heterosubtypic IAV strains ${ }^{11,13-15}$. Human studies are consistent with murine data. Namely, published evidence shows that prominence of influenza-specific $\mathrm{CD}^{+}{ }^{+} \mathrm{T}$ cells correlates with lower viral titers ${ }^{16}$ and decreased disease severity ${ }^{17-19}$ during IAV infection. Furthermore, $\mathrm{CD}^{+} \mathrm{T}$ cells primed with seasonal circulating IAV strains can cross-react with pandemic H1N1 (pH1N1) or variant seasonal peptides ${ }^{20-22}$ or virulent H7N9 and H5N1 avian IAV-derived peptides ${ }^{23-26}$. Together, these data suggest that an IAV-specific $\mathrm{CD}^{+} \mathrm{T}$ cell-mediated vaccine can provide broad cross-reactive immunity across distinct influenza A strains and subtypes for both conserved and variable CD8 ${ }^{+} \mathrm{T}$ cell epitopes.

It is well established that $\mathrm{CD}^{+} \mathrm{T}$ cells with diverse $\mathrm{T}$ cell receptor (TCR) repertoires are greatly beneficial for disease outcome, contributing to reduced disease severity ${ }^{27}$, enhanced $\mathrm{CD}^{+}$ $\mathrm{T}$ cell function ${ }^{28}$, cross-reactivity across different peptide variants 29,30 , and preventing viral escape ${ }^{31,32}$. Importantly, although $\mathrm{CD} 8{ }^{+}$TCRs are typically highly specific for their cognate peptide, they can also recognize a broad range of peptide variants, thus allowing $\mathrm{CD} 8^{+} \mathrm{T}$ cells to have a powerful capacity to recognize not only their cognate peptide but also a range of viral mutants ${ }^{11,30,33-36}$. In case of highly mutating influenza viruses, such cross-reactive $\mathrm{CD}^{+}{ }^{+} \mathrm{T}$ cells are highly desirable as they elicit immune responses towards multiple viral strains and hence provide cross-strain protection.

The precise mechanisms underlying cross-recognition by influenza-specific $\mathrm{CD}^{+}$TCRs in humans are unclear. To date, TCR $\beta$ repertoires have only been dissected for two immunodominant influenza-specific human epitopes, HLA-A ${ }^{\star} 02: 01$ restricted $\mathrm{M}_{58}{ }^{30}$ and $\mathrm{HLA}-\mathrm{B}^{\star} 35: 01{ }^{\star} 35: 03 /^{\star} 07: 02$-restricted $\mathrm{NP}_{418}{ }^{30}$, providing $\sim 50 \%$ of the cumulative population coverage. Thus it is important to understand cross-reactivity and diversity of $\mathrm{CD}^{+} \mathrm{T}$ cell TCR $\beta$ repertoires directed against other prominent IAV-specific epitopes, if we are to rationally design a broadly protective $\mathrm{CD} 8^{+} \mathrm{T}$ cell-mediated influenza vaccine.

Here we use an ex vivo multiplex reverse transcription polymerase chain reaction (RT-PCR) approach ${ }^{30,37,38}$ to analyze paired TCRa $\beta$ repertoires for two additional prominent human $\mathrm{CD}^{+} \mathrm{T}$ cell epitopes, HLA-B ${ }^{\star} 37$ :01-restricted $\mathrm{NP}_{338-346^{-}}$ FEDLRVLSF $\left(\mathrm{NP}_{338}\right)^{39}$ and HLA-A ${ }^{\star} 01: 01$-restricted $\mathrm{NP}_{44-52}$ CTELKLSDY $\left(\mathrm{NP}_{44}\right)^{23,40}$, restricted by alleles that are frequent in the human population ( $\sim 19 \%$ of the cumulative coverage). We identify cross-reactive TCR $\alpha \beta$ clonotypes capable of recognizing the wild-type (WT) peptide and peptide variants. This is most prominent in HLA-B ${ }^{\star} 37: 01$-expressing donors, where distinct and cross-reactive $\mathrm{NP}_{338}$-specific TCR $\alpha \beta$ clonotypes bound each of the $\mathrm{NP}_{338}$-WT, $\mathrm{NP}_{338}$-L7S, and $\mathrm{NP}_{338}$-V6L variants $(93-100 \%$ of distinct IAV strains), highlighting their potential to provide protection against distinct influenza strains and subtypes. Our structural analysis reveals that the variants adopt a similar conformation than the WT epitope for both HLA-A*01:01 (HLA-A1)

\section{Table 1 HLA alleles predicted to bind the WT NP $\mathbf{P 3 8 - 3 4 6}_{33}$ FEDLRVLSF peptide}

\begin{tabular}{|c|c|c|c|}
\hline $\begin{array}{l}\text { Prediction score } \\
\text { range }\end{array}$ & HLA allele & Prediction score & HLA superfamily \\
\hline \multirow[t]{3}{*}{$>20$} & $B \star 37$ & 33 & B44 \\
\hline & $B \star 44: 02$ & 25 & B44 \\
\hline & $B \star 18$ & 22 & B44 \\
\hline \multirow[t]{9}{*}{$15-20$} & $\mathrm{~B}^{\star} 08$ & 17 & B8 \\
\hline & $B \star 40: 01$ & 17 & B44 \\
\hline & $B \star 45: 01$ & 17 & B44 \\
\hline & $B \star 41: 01$ & 16 & ND \\
\hline & $B^{\star} 14: 02$ & 15 & B27 \\
\hline & $B \star 53: 01$ & 15 & B7 \\
\hline & $B \star 38: 01$ & 15 & B27 \\
\hline & $B^{\star} 13$ & 3 & ND \\
\hline & $A^{\star} 68: 01$ & 2 & A3 \\
\hline \multicolumn{4}{|c|}{$\begin{array}{l}\text { The http://www.syfpeithi.de/bin/MHCServer.dll/Info.htm prediction tool was used to assign a } \\
\text { prediction score that the WT NP } 338 \text { peptide would be bound by the particular HLA allele. } \\
\text { Prediction scores were grouped into a predicted score range for clarity. ND refers to HLA alleles, } \\
\text { which have not been assigned a HLA superfamily. Alleles in bold were selected for further } \\
\text { analysis }\end{array}$} \\
\hline
\end{tabular}

and HLA-B³7:01 (HLA-B37) molecules, providing a molecular basis for $\mathrm{CD}^{+}{ }^{+} \mathrm{TCR} \alpha \beta$ cross-reactivity. Structural analysis indicates that molecular similarity may underpin how an HLA-B37restricted cross-reactive TCR $\alpha \beta$, clone $\mathrm{EM} 2$, can recognize the variants. Thus our data suggest that structural resemblance underpins cross-reactivity of HLA-B $37^{+} \mathrm{NP}_{338}{ }^{+} \mathrm{CD} 8^{+}$and HLA$\mathrm{Al}^{+} \mathrm{NP}_{44}{ }^{+} \mathrm{CD} 8{ }^{+} \mathrm{T}$ cells, despite their diverse TCR repertoires between individuals towards those two epitopes.

\section{Results}

Only HLA-B37 ${ }^{+}$donors elicit a $\mathrm{NP}_{388}{ }^{+} \mathrm{CD8}^{+} \mathrm{T}$ cell response. Our previous work identified $\mathrm{NP}_{338}$ as an immunodominant CD8 $+\mathrm{T}$ cell epitope in individuals expressing HLA-B37 ${ }^{39}$. However, $\mathrm{NP}_{338}$ was previously reported to be restricted by HLA-B ${ }^{\star} 44: 03^{41}$. Thus we first investigated whether the $\mathrm{NP}_{338}$ peptide can be presented by other HLA allomorphs using the online SYFPETHI peptide-binding prediction tool ${ }^{42}$. A high prediction binding score for the $\mathrm{NP}_{338}$ peptide was obtained for HLA-B37, HLA-B ${ }^{\star} 44: 02$, and HLA-B ${ }^{\star}$ 18:01 (HLA-B18) (Table 1). The SYFPETHI website contains only the HLA-B ${ }^{\star} 44: 02$ in its database but not the closely related allomorphs, such as HLA-B ${ }^{\star} 44: 03$ and HLA-B ${ }^{\star} 44: 05^{43}$. The high prediction binding score for the $\mathrm{NP}_{338}$ peptide obtained for HLA-B ${ }^{\star} 44: 02$ is likely to be shared by HLA-B ${ }^{\star} 44: 03$ and HLA$\mathrm{B}^{\star}$ 44:05 (HLA-B44), given their known overlapping peptide repertoire $^{44}$. Both HLA-B44 $4^{44-47}$ and HLA-B18 ${ }^{46,48}$ display a preference for $\mathrm{P} 2-\mathrm{E}$ and $\mathrm{P} \Omega-\mathrm{F} / \mathrm{Y}$ in their bound peptides, and both residues are present in the IAV-derived $\mathrm{NP}_{338}$ peptide.

We first refolded the $\mathrm{NP}_{338}$ peptide with HLA-B37, HLA-B18, and HLA-B44 molecules and assessed the stability of each peptide-HLA (pHLA) complex. We used HLA-B ${ }^{\star}$ 44:05 molecule as the refold yield was higher for this allomorph than for the HLA$B^{\star} 44: 02 / 03$. The $\mathrm{NP}_{338}$ peptide could bind each of the three HLA molecules (HLA-B37, -B18, and $-\mathrm{B}^{\star} 44: 05$ ); however, the stability of HLA-B37-NP ${ }_{338}$ was superior by $6{ }^{\circ} \mathrm{C}$ to HLA-B18-NP 338 and by $14^{\circ} \mathrm{C}$ to $\mathrm{HLA}-\mathrm{B}^{\star} 44: 05-\mathrm{NP}_{338}$ (Supplementary Table 1 ).

We then solved the binary structures of the $\mathrm{NP}_{338}$ peptide presented by HLA-B37, HLA-B18, and HLA-B44 (Supplementary Table 2, Fig. 1). The $\mathrm{NP}_{338}$ peptide adopted an extended conformation in the cleft of HLA-B37, with the P2-Glu and P9Phe acting as anchor residues in the B- and F-pocket of HLA-B37, respectively ${ }^{49}$. In addition to the primary anchor residues, the $\mathrm{P} 5$ Arg acted as a secondary anchor residue, fully buried into the Fpocket, and formed a salt bridge with Asp77 from the a1-helix in the HLA-B37 molecule (Fig. 1a). The remaining six residues were 
a
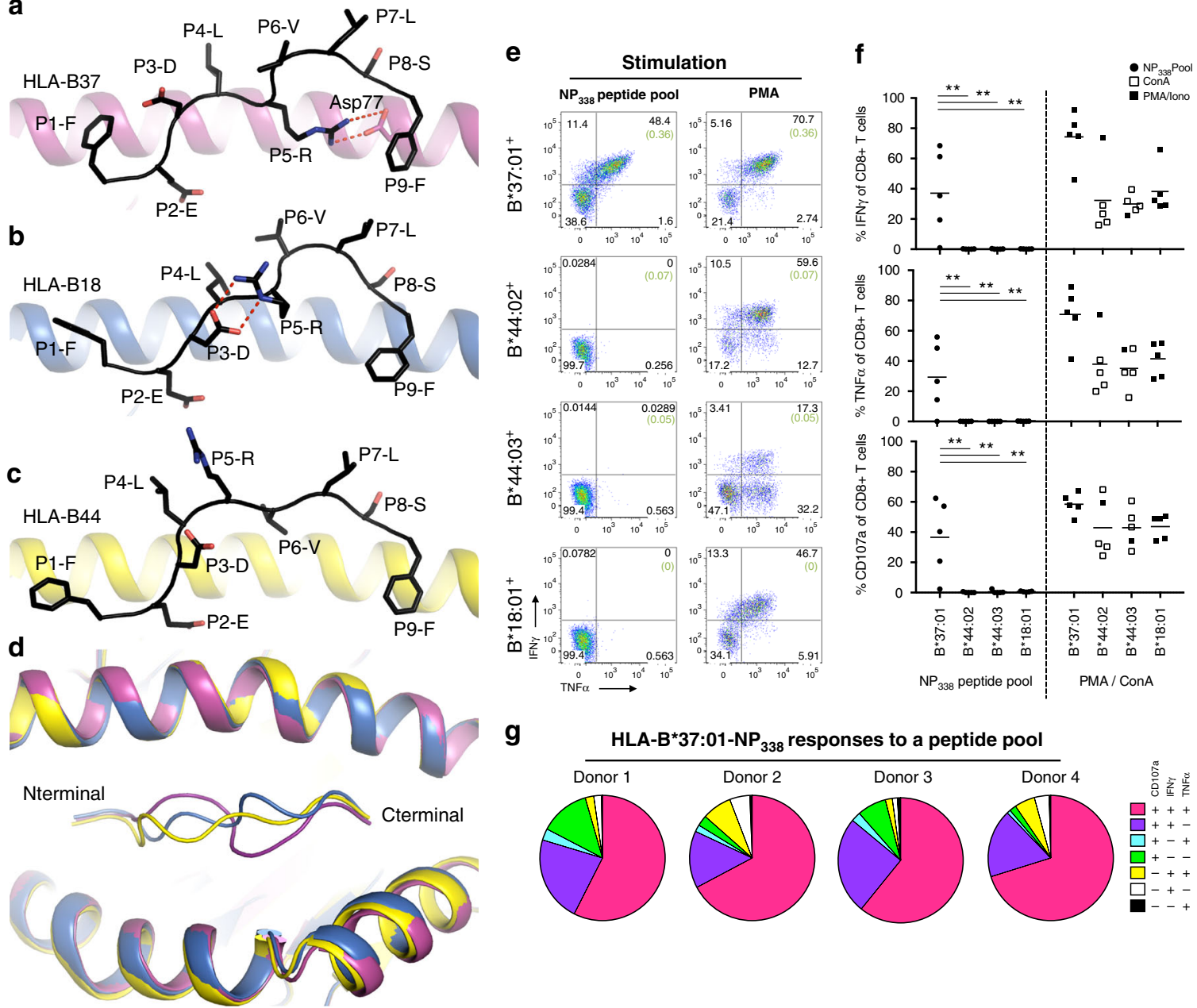

$\mathrm{NP}_{338}$ peptide pool

PMA / ConA

\section{g}

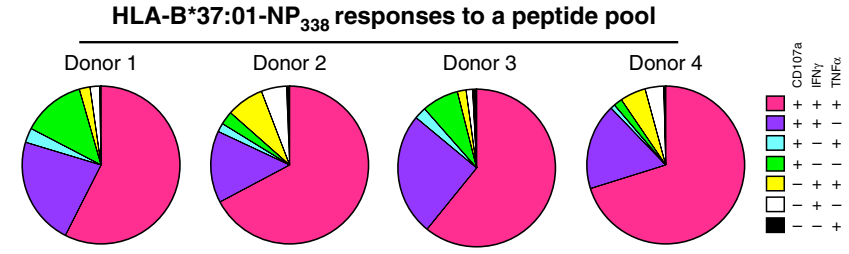

Fig. $1 \mathrm{NP}_{338}$ elicits robust $C D 8^{+} \mathrm{T}$ cell responses only in the context of HLA-B*37:01. a-d Crystal structures of $\mathbf{a} H L A-B \star 37: 01$ (purple), b HLA-B*18:01 (blue), and $\mathbf{c}$ HLA-B*44:05 (yellow) in complex with NP 338 WT (represented in black stick). $\mathbf{d}$ is showing an overlay of the three peptide-HLA complexes in cartoon representation, with $\mathrm{NP}_{338}$ colored accordingly to the bound HLA, namely, purple (HLA-B*37:01), blue (HLA-B*18:01), and yellow (HLA-B*44:05). e-g PBMCs from HLA-B ${ }^{\star} 37: 01^{+}$donors $(n=5), \mathrm{HLA}-\mathrm{B}^{\star} 44: 02^{+}$donors $(n=5), \mathrm{HLA}-\mathrm{B}^{\star} 44: 03^{+}$donors $(n=5)$, or HLA-B*18:01+ donors $(n=5)$ were stimulated with a pool of $\mathrm{NP}_{338}$ peptides $\left(10 \mu \mathrm{M}\right.$ each peptide, $30 \mu \mathrm{M}$ total), and specificity was assessed in an ICS assay against $3 \mu \mathrm{M} N \mathrm{P}_{338}$ pool $(1 \mu \mathrm{M}$ each peptide, $H L A-B^{\star} 44: 02^{+}$donors) directly into the well or $30 \mu \mathrm{M}$ (10 $\mu \mathrm{M}$ each peptide, all other donors) NP $338-$ pooled pulsed $A P C$ lines ( $H L A-B^{\star} 37: 01$, HLA-B*44:03, and HLA-B*18:01). CD8 ${ }^{+}$T cells are gated on lymphocytes, singlets, live ${ }^{+}$(when stained with the second antibody cocktail only) CD3mid-high $\mathrm{CD}^{+} \mathrm{T}$ cells; as per Supplementary Fig. $2 \mathrm{a}$. e Representative dot plots of IFN $\gamma^{+} \mathrm{TNF} \alpha^{+}$production by pooled $\mathrm{CD} 8^{+} \mathrm{T}$ cell lines derived from HLA-B $37: 01^{+}$ $\mathrm{HLA}-\mathrm{B}^{\star} 44: 02^{+}, \mathrm{HLA}-\mathrm{B}^{\star} 44: 03^{+}$, or HLA-B*18:01+ donors, towards a pool of NP 338 peptides. No peptide control represented in brackets. f Summary of IFN $\gamma$, TNF $\alpha$, and CD107a production, minus no peptide controls, against the pool of NP 338 peptides (closed circle) or a positive control (ConA open square or PMA closed square) across multiple donors. Statistical analysis using a Dunnett's two-way ANOVA in which ${ }^{\star} p \leq 0.05$, ${ }^{\star \star} p \leq 0.01$, and ${ }^{\star \star \star} p \leq 0.001$. g Summary of the polyfunctional profiles, minus background, from the four HLA-B^37:01+ donors who responded towards the pool of $\mathrm{NP}_{338}$ peptides

all solvent exposed and represented potential contacts for the TCR. Comparison of the HLA-B37-NP 338 with HLA-B18-NP 338 and HLA-B44- $\mathrm{NP}_{338}$ complexes show an overall similar HLAbinding cleft (Fig. 1d), with a root mean square deviation (r.m.s. d.) of 0.2 and $0.4 \AA$, respectively. Similar to the HLA-B37-NP 338 structure, the $\mathrm{NP}_{338}$ peptide was anchored to HLA-B18 and HLAB44 by $\mathrm{P} 2-\mathrm{Glu}$ and $\mathrm{P} 9-\mathrm{Ph}$. However, the $\mathrm{NP}_{338}$ peptide adopted a strikingly distinct conformation when bound to HLA-B37 as compared with HLA-B18 (r.m.s.d. of the peptide $1.7 \AA$ ) and HLA-B44 (r.m.s.d. of $1.8 \AA$ for the peptide). In HLA-B18, P5-Arg is partially buried in the $\mathrm{D}$-/E-pocket and only exposed its guanidinium group to the solvent, stabilized by a salt bridge with the peptide P3-Asp (Fig. 1b). Polymorphism at position 116 between the two HLA molecules change the architecture of the peptide. The HLA-B18 contains a small Ser116, while the HLAB37 has a large Phe116. As a result, P9-Phe of the peptide is anchored deeper in the cleft in the HLA-B18 molecule, which would sterically clash with the P5-Arg conformation observed in HLA-B37. In addition, the salt bridge observed in HLA-B37 between Asp77 and P5-Arg would be lacking in HLA-B18 due to the presence of Ser77. In HLA-B44, P5-Arg was fully exposed to the solvent (Fig. 1c). Owing to the presence of four tyrosine residues $(9,74,99,116)$ in the cleft of HLA-B44 located underneath P5-Arg, Arg cannot be accommodated inside the cleft and adopt a different conformation from the one observed in HLA-B37, that only shares Tyr74. The additional anchor residue observed in the $\mathrm{B} 37-\mathrm{NP}_{338}$ complex could explain the higher stability of this pHLA complex (Supplementary Table 1). These distinct conformations adopted by the $\mathrm{NP}_{338}$ peptide, due to HLA polymorphism, changed the surface presented to the TCR. On one hand, the $\mathrm{NP}_{338}$ peptide revealed a hydrophobic surface when bound to HLA-B37, while on the other, it was an epitope with central positively charged residues in the cleft of HLA-B18 and HLA-B44. 
Table 2 Conservation of $\mathrm{NP}_{338}$ epitope in distinct IAV strains

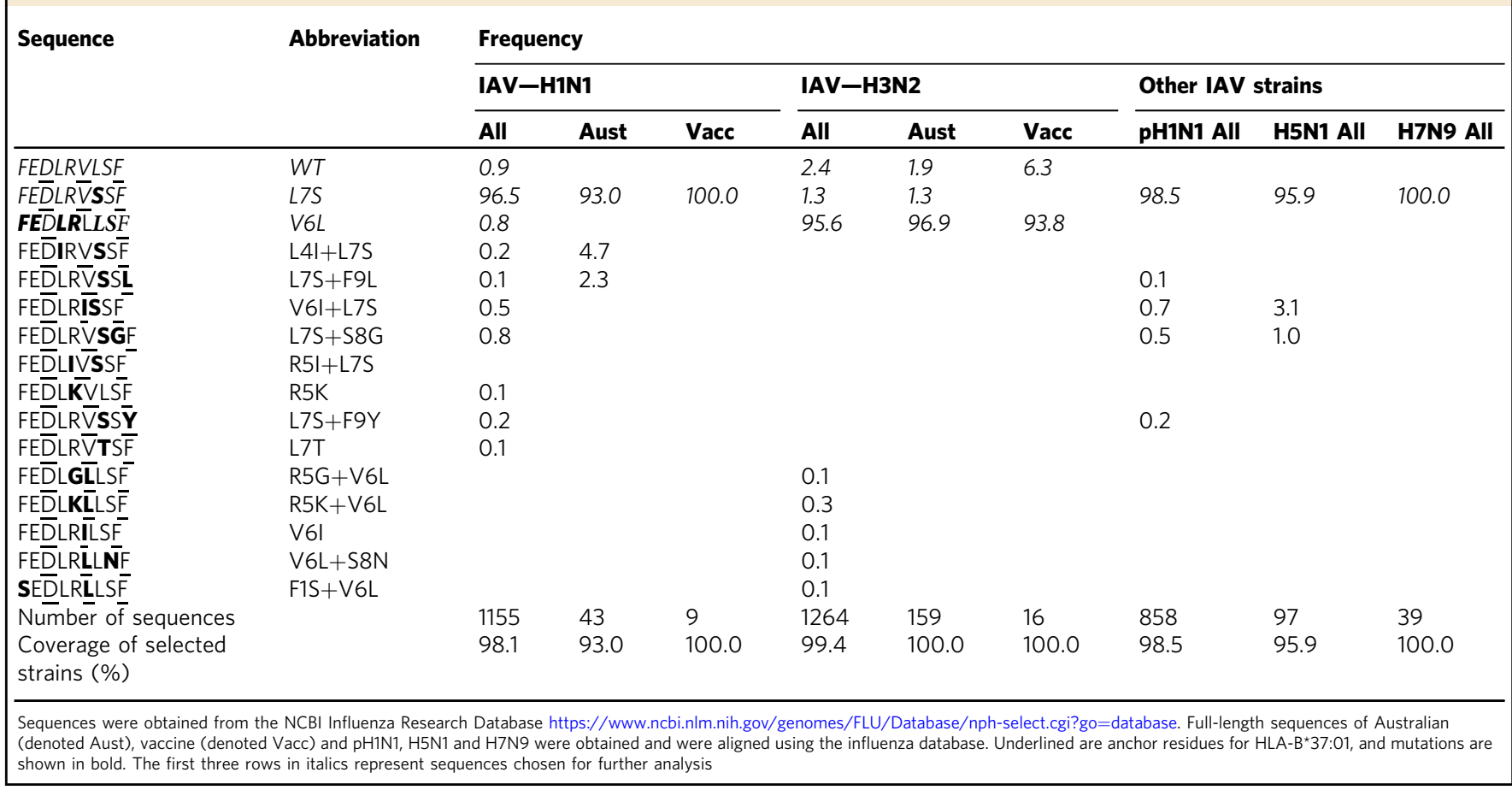

We next probed memory $\mathrm{NP}_{338}{ }^{+} \mathrm{CD} 8{ }^{+} \mathrm{T}$ cell responses in individuals expressing HLA-B ${ }^{\star} 37: 01$, HLA-B ${ }^{\star} 44: 02$, HLA$B^{\star} 44: 03$, or HLA- $B^{\star}$ 18:01 (Fig. 1e-g, Supplementary Table 3 ) by stimulating their peripheral blood mononuclear cells (PBMCs) with a pool of $\mathrm{NP}_{338}$ peptides corresponding to the main variants in the circulating influenza A strains (Table 2). Following 10-16 days of peptide stimulation, we detected robust $\mathrm{CD}^{+} \mathrm{T}$ cell responses by interferon- $\gamma$ (IFN $\gamma)$ and tumor necrosis factor- $\alpha$ (TNFa) production as well as CD107a expression in the majority $(4 / 5)$ of HLA-B37 ${ }^{+}$donors (Fig. 1f, g), with a high level of polyfunctionality (Fig. 1g). However, $\mathrm{NP}_{338}+\mathrm{CD}^{+} \mathrm{T}$ cell responses were undetectable in all (5/5) HLA-B ${ }^{\star} 44: 02$, HLA$B^{\star} 44: 03$, or HLA- ${ }^{\star}$ 18:01 individuals (Fig. 1f, g), despite their CD8 $+\mathrm{T}$ cells having responded strongly to non-specific stimulation by phorbol 12-myristate 13-acetate or Concanavalin A (Fig. 1f).

Overall, these data suggest that HLA-B37, but not HLA-B44 or HLA-B18, represents the HLA restriction for the $\mathrm{NP}_{338}$ peptide. The lack of $\mathrm{NP}_{338}{ }^{+} \mathrm{CD} 8{ }^{+} \mathrm{T}$ cell responses in the context of HLAB44 and HLA-B18 might be due to the distinct conformations, or lower stability, of $\mathrm{NP}_{338}$ as compared to HLA-B37.

Cross-reactive $\mathrm{NP}_{338}{ }^{+} \mathrm{CD8}^{+} \mathrm{T}$ cells towards $\mathrm{NP}_{338}$ variants. Having shown robust $\mathrm{NP}_{338}{ }^{+} \mathrm{CD} 8{ }^{+} \mathrm{T}$ cell responses in HLA-B37 donors, we next determined the level of cross-recognition towards the main $\mathrm{NP}_{338}$ variants occurring in IAVs. Our conservation analysis of the $\mathrm{NP}_{338}$ viral peptides across vaccine and circulating IAV strains, including $\mathrm{pH} 1 \mathrm{~N} 1, \mathrm{H} 5 \mathrm{~N} 1$, and $\mathrm{H} 7 \mathrm{~N} 9$, found 16 natural variants of $\mathrm{NP}_{338}$ peptide (Table 2), with the most common mutations occurring at position (P) 5, 6, and 7 of the peptide. Two major variants; FEDLRVSSF ( $\mathrm{NP}_{338}$-L7S) and FEDLRLLSF $\left(\mathrm{NP}_{338}\right.$-V6L) were dominant in $\mathrm{H} 1 \mathrm{~N} 1$, $\mathrm{pH} 1 \mathrm{~N} 1, \mathrm{H} 5 \mathrm{~N} 1$, and $\mathrm{H} 7 \mathrm{~N} 9$ or $\mathrm{H} 3 \mathrm{~N} 2$ strains, respectively, representing $93-100 \%$ of the distinct strains and were thus selected in addition to the previously published (WT) peptide for further analysis.

To assess the cross-reactive potential of HLA-B37- $\mathrm{NP}_{338}{ }^{+} \mathrm{CD} 8{ }^{+}$ $\mathrm{T}$ cells, pooled or variant-specific $\mathrm{NP}_{338} \mathrm{~T}$ cell lines were generated using PBMCs from $\mathrm{HLA}-\mathrm{B} 37^{+}$donors. We also generated HLA-B37-NP 338 and mutant HLA-B37-NP $338^{-V 6 L}$ and HLA-B37-NP 338 -L7S tetramers. The ability to recognize, and functionally respond, to each of the $\mathrm{NP}_{338}$ variant was then assessed using tetramers and an intracellular cytokine staining assay, respectively (Fig. 2). Staining with all three pHLA tetramers and functional assays showed similar proportions of $\mathrm{CD}^{+} \mathrm{T}$ cell staining/functional levels in all WT or variant-specific $\mathrm{NP}_{338^{-}} \mathrm{T}$ cell lines (Fig. 2a, c), suggesting that the majority of $\mathrm{NP}_{338^{-}}$ specific $\mathrm{CD}^{+} \mathrm{T}$ cell lines were able to cross-recognize (Fig. 2a, c) and respond to (Fig. 2b, c) each of the three distinct peptides, indicating broad cross-reactivity towards these epitopes (Fig. 2b, c). Interestingly, the $\mathrm{NP}_{338^{-}}$V6L tetramer showed a slightly stronger staining than the WT and $\mathrm{NP}_{338}$-L7S tetramers (Fig. 2a).

$\mathrm{CD}^{+} \mathrm{T}$ cell lines typically recognized and responded most prominently to the peptide they were generated against, with the lowest level of cross-reactivity being observed by the $\mathrm{NP}_{338}$-V6Lspecific $\mathrm{CD}^{+} \mathrm{T}$ cell lines, when stimulated with the $\mathrm{NP}_{338}-\mathrm{WT}$ $(21.45 \pm 18.86 \%$ by tetramer, $20.98 \pm 19.80 \%$ by IFN $\gamma$, and $18.88 \pm 18.90 \%$ by $\mathrm{TNF} \alpha)$ and $\mathrm{NP}_{338}$-L7S variant $(16.31 \pm 14.47 \%$ by tetramer, $13.63 \pm 12.04 \%$ by IFN $\gamma$, and $13.04 \pm 11.65 \%$ by $\mathrm{TNF} \alpha$ ). These data suggest that a high level of cross-reactivity across different variants exists, although some variant-specific reactivity can be also detected. These data highlight that such cross-reactive CD8 ${ }^{+} \mathrm{T}$ cells may offer protection against $\mathrm{H} 1 \mathrm{~N} 1$, H5N1, H7N9, and possibly other novel IAV strains.

To further assess whether the $\mathrm{WT} \mathrm{NP}_{338}$ peptide elicited $\mathrm{CD}^{+}$ $\mathrm{T}$ cell responses of high functional avidity, $\mathrm{CD} 8^{+} \mathrm{T}$ cell lines were generated against the WT $\mathrm{NP}_{338}$ peptide $(n=3)$, and their functional response was assessed towards decreasing concentrations of the $\mathrm{WT} \mathrm{NP}_{338}$ peptide (Fig. 2d). All data were normalized to the maximal response (when stimulated with maximum peptide). High and stable functional avidity towards $\mathrm{NP}_{338}(\mathrm{IFN} \gamma$, TNFa, and CD107a) was observed in cell lines derived from all three donors (Fig. 2d).

Our data show that HLA-B $37^{+}$individuals display polyfunctional and highly cross-reactive $\mathrm{CD}^{+} \mathrm{T}$ cell response to the $\mathrm{NP}_{338}$ epitope and its major variants. 
a

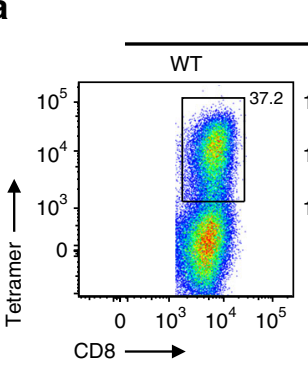

HLA-B*37:01 NP ${ }_{338}$ Tetramer
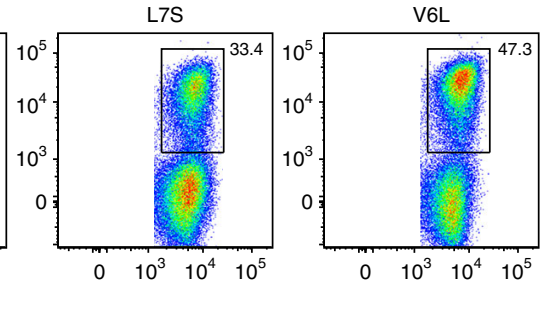

b

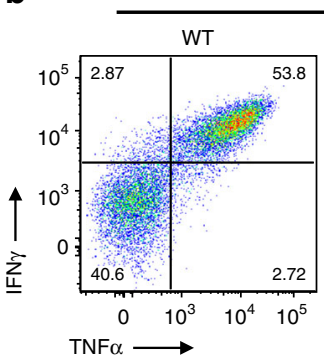

$\mathrm{NP}_{338}$ Peptide variant
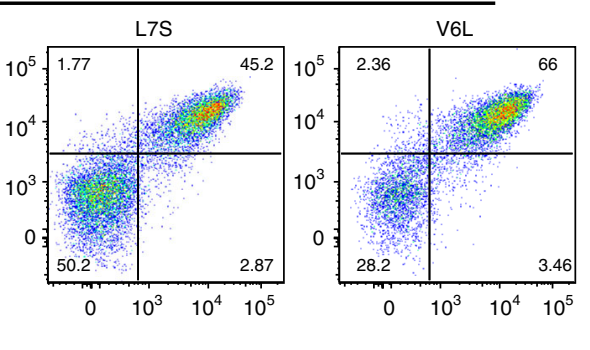

c
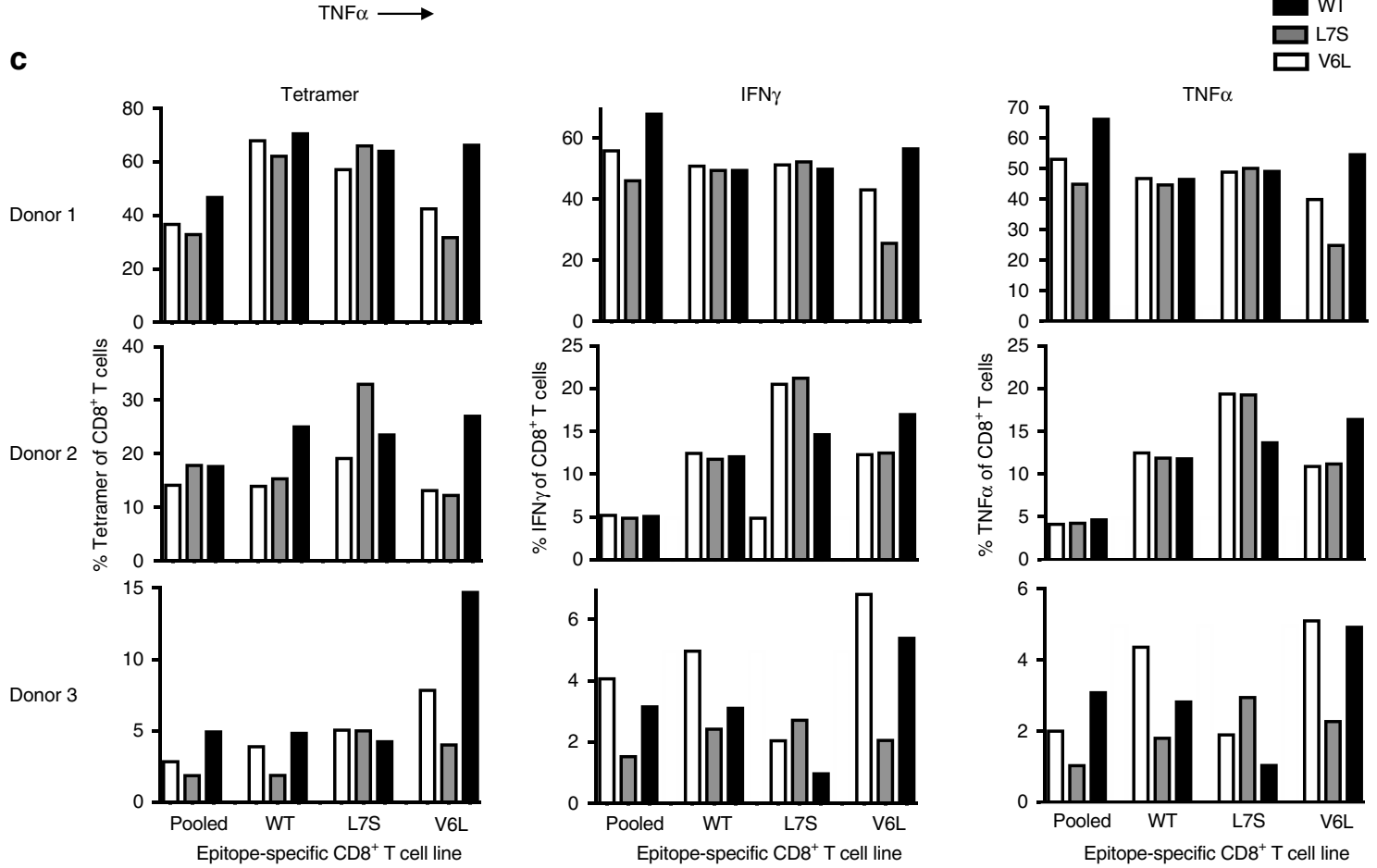

d

O Donor 1 Donor 2 Donor 4

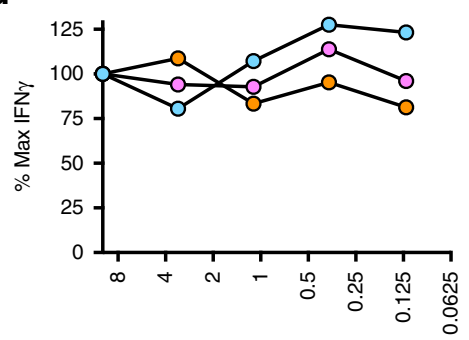

Peptide concentration $(\mu \mathrm{M})$

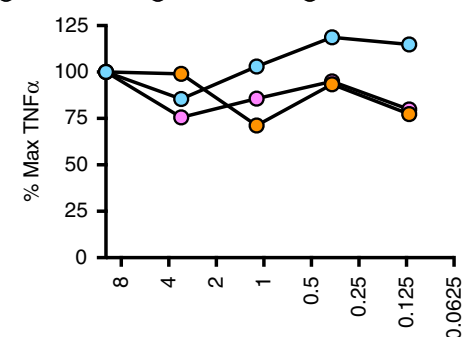

Peptide concentration $(\mu \mathrm{M})$

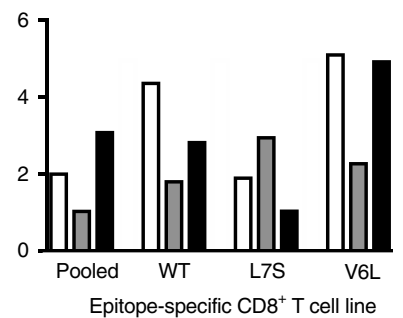

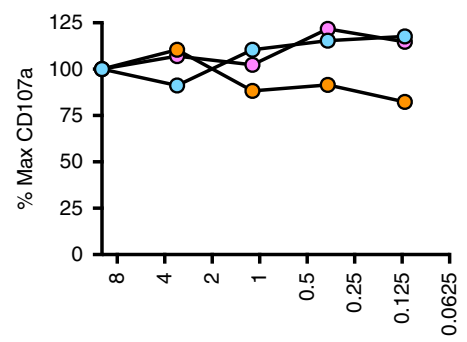

Peptide concentration $(\mu \mathrm{M})$
$\mathrm{NP}_{338}$ variants are molecular mimics of the $\mathrm{WT} \mathrm{NP}_{338}$ epitope. To understand the molecular basis of HLA-B37- $\mathrm{NP}_{338}{ }^{+} \mathrm{CD} 8^{+} \mathrm{T}$ cell cross-reactivity, we solved the structures of two major $\mathrm{NP}_{338}$ variants, namely, $\mathrm{NP}_{338}-\mathrm{V} 6 \mathrm{~L}$ and $\mathrm{NP}_{338}$ - $\mathrm{L} 7 \mathrm{~S}$ in complex with HLA-B37 (Fig. 3; Supplementary Table 2). Both peptides bound HLA-B37 in an extended conformation with the canonical P2-
Glu and P9-Phe ${ }^{49}$, while P5-Arg acted as a secondary anchor residue (Fig. 3a, b). Superimposition of the HLA-B37-NP 338 binding cleft with either HLA-B37-NP ${ }_{338}$-V6L (Fig. 2c) or HLAB37-NP ${ }_{338}$-L7S (Fig. 2d) revealed a similar conformation of the HLA-binding cleft (r.m.s.d. of $0.08 \AA$ ). In addition, the peptides adopted a similar conformation as the $\mathrm{NP}_{338}$ peptide with an r.m. 
Fig. $2 \mathrm{NP}_{338}$-specific CD8 ${ }^{+} \mathrm{T}$ cell lines cross-react with variant $\mathrm{NP}_{338}$ peptides. PBMCs from HLA-B $37: 01^{+}$donors $(n=4)$ were stimulated with a pool $\left(10 \mu \mathrm{M}\right.$ each, $30 \mu \mathrm{M}$ total) or individual $(10 \mu \mathrm{M}) \mathrm{NP}_{338}$ peptides for 10-11 days and cross-reactivity was assessed by tetramer staining and ICS assays. Gating strategy: lymphocytes, singlets, live+, CD3mid-high, CD8 ${ }^{+}$T cells; as per Supplementary Figure 2a, b. a Representative dot plots of a pooled NP $338^{-}$

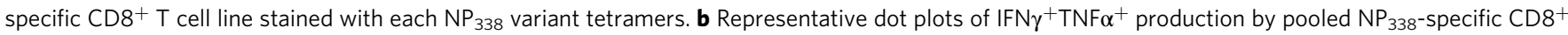
T cells. c Summary of tetramer staining, IFN $\gamma$ (minus no peptide control), and TNF $\alpha$ (minus no peptide control) production by pooled or variant-specific $\mathrm{NP}_{338}$-specific CD8 ${ }^{+} \mathrm{T}$ cell lines in Donors 1-3. d Summary of IFN $\gamma$, TNF $\alpha$, and CD107a production, minus no peptide control, of WT-specific CD8 ${ }^{+} \mathrm{T}$ cell lines from Donors 1,2 , and 4 in response to concentrations ranging between $10 \mu \mathrm{M}$ and $0.125 \mu \mathrm{M}$ of the WT-NP 338 peptide. Values are represented as a proportion of maximum tetramer staining or cytokine production against the line-specific peptide

s.d. of 0.12 and $0.09 \AA$, respectively (Fig. 3e, f). The hydrophobic P6-Val residue sits near the a2-helix and interacts with Val152, Gln155, and Asp156 of the HLA (Fig. 3g). The substitution of P6Val for P6-Leu in the H3N2 was readily accommodated in the HLA-B37 cleft and did not change either the peptide or HLA conformation (Fig. 3h). The P7-Leu residue sits above Trp147, with its side chain interacting with Ala150, Val152, and Lys146 (Fig. 3i). The substitution from P7-Leu to P7-Ser did not impact the conformation of either the peptide or HLA molecule (Fig. 3j). We also showed that the two $\mathrm{NP}_{338}$ variants could stabilize HLAB37 as efficiently as the $\mathrm{NP}_{338}$ WT peptide (Supplementary Table 1).

Overall, the two major variants of the $\mathrm{NP}_{338}$ epitope adopted the same conformation as the $\mathrm{NP}_{338}$ epitope and represent molecular mimics of the WT peptide, which might favor $\mathrm{T}$ cell cross-reactivity.

Key TCRs cross-recognize $\mathrm{NP}_{338}$ variants directly ex vivo. To investigate HLA-B37- $\mathrm{NP}_{338}{ }^{+} \mathrm{CD}^{+} \mathrm{T}$ cell cross-reactivity at a molecular level, PBMCs from healthy HLA-B37 ${ }^{+}$donors $(n=3)$ were stained with $\mathrm{WT}$ and variant HLA-B37-NP 338 tetramers individually, magnetically enriched, and single-cell sorted. TCR $\alpha \beta$ repertoire was determined using a multiplex RT-PCR ${ }^{37}$. As expected, prominent $\mathrm{CD}^{+} \mathrm{T}$ cell memory pools could be detected directly ex vivo using $\mathrm{NP}_{338}, \mathrm{NP}_{338^{-}} \mathrm{V} 6 \mathrm{~L}$, and $\mathrm{NP}_{338}$ - $\mathrm{L} 7 \mathrm{~S}$ tetramers (Fig. 4a), with magnetic enrichment increasing the proportion of $\mathrm{NP}_{338}$-specific $\mathrm{CD}^{+} \mathrm{T}$ cells $>100$-fold. $\mathrm{CD}^{+}$ $\mathrm{T}$ cells directed at the HLA-B37- $\mathrm{NP}_{338}$ epitopes in healthy donors were of the memory phenotypes characterized by CD27hi and CD45RA low-med expression (Fig. 4a). Interestingly, $\mathrm{NP}_{338}$-V6Lspecific $\mathrm{CD}^{+} \mathrm{T}$ cells were found at the highest average frequency, at 1 in every $5.97 \times 10^{-4} \mathrm{CD}^{+} \mathrm{T}$ cells, followed by $\mathrm{NP}_{338}$ and then $\mathrm{NP}_{338^{-L}}$ - $\mathrm{S}$-specific CD8 ${ }^{+} \mathrm{T}$ cells found at frequencies of 1 in $2.31 \times 10^{-4}$ and $1.86 \times 10^{-4} \mathrm{CD}^{+} \mathrm{T}$ cells, respectively (Fig. 4b).

The TCR $\alpha \beta$ repertoire across all three donors (Fig. 5, Supplementary Table 4) was entirely private, meaning no shared TCR $\alpha \beta$ s were detected between the donors, and of comparable diversity, comprising $13.67 \pm 5.77,11.67 \pm 0.58$, and $10.33 \pm 2.08$ distinct TCR $\alpha \beta$ clonotypes (Donors $1-3$, respectively). A TRBV19 bias was detected in all donors $(19.01 \pm 18.54 \%, 39.88 \pm 27.32 \%$, and $37.36 \pm 33.49 \%$ in Donors $1-3$, respectively), while Donor 1 displayed an additional TRBV27 bias (26.01 $\pm 16.12 \%$; Fig. 5, Supplementary Table 4). Interestingly, only one or two highfrequency but unique clonotypes were able to cross-recognize all three $\mathrm{NP}_{338}$ variants, and $69.24 \pm 16.65 \%, 44.25 \pm 34.87 \%$, and $53.45 \pm 5.76 \%$ cross-reactivity was observed in Donors 1-3, respectively. Interestingly, each of these donors utilized different pairings to achieve universal cross-reactivity. Donor 1 favored TRAV14/TRBV20-1 and TRAV29/TRBV27, Donor 2 TRAV35/ TRBV19, and Donor 3 TRAV23/TRBV27 and TRAV21/TRBV9 pairings (Supplementary Table 4 ). In addition, TRBV19+ ${ }^{+}$crossreactive TCR clonotypes were detected in all donors.

With respect to the CDR3 $\alpha / \beta$ length, 9-mer CDR3 $\alpha$ and 9-10mer CDR3 $\beta$ loops were preferentially used for the recognition of $\mathrm{NP}_{338}$ (Fig. 5b, c). Together, these data highlight the potential of common HLA-B37- $\mathrm{NP}_{338}{ }^{+} \mathrm{CD} 8{ }^{+} \mathrm{TCR} \alpha \beta$ clonotypes to provide protection against distinct IAV strains.

The frequency of cross-reactivity was increased $(81.35 \pm$ $19.72 \%$ ) following in vitro expansion with the $\mathrm{WT} \mathrm{NP}_{338}$ peptide (Supplementary Fig. 1). Donor 3's TCR $\alpha \beta$ repertoire was more restricted following in vitro amplification comprising fewer distinct clonotypes $(7.33 \pm 2.08)$ and displayed a stronger TRBV19 bias (Supplementary Fig. 1ab). Again, 7-10-mer CDR3a and 8-9-mer CDR3 $\beta$ lengths were preferred in the recognition of $\mathrm{NP}_{338}$ (Supplementary Fig. 1c). A single TCR $\alpha \beta$ clonotype (termed EM2: TRAV30/TRBV19, CDR3a: CGTERSGGYQKVTF, and CDR3 $\beta$ : CASSMSAMGTEAFF) was able to cross-react with all three $\mathrm{NP}_{338}$ peptides, therefore providing universal HLA-B37$\mathrm{NP}_{338}{ }^{+} \mathrm{CD}^{+}$recognition.

Overall, despite entirely private TCR $\alpha \beta$ repertoires being detected within each individual, a high level of inter-variant cross-reactivity was achieved in each donor, facilitated by key TCRs.

Biased TRBV19+ ${ }^{+}$TCR chains mainly contacts the HLA-B37. To further understand the molecular mechanism underlying $\mathrm{T}$ cell cross-reactivity, we then investigated the cross-reactive clonotype described above (EM2 TCR; TRAV30/TRBV19, Supplementary Table 4) that was able to recognize $\mathrm{NP}_{338}$ and its two most common variants. We solved the structure of the EM2 TCR in complex with HLA-B37- $\mathrm{NP}_{338}$ (Supplementary Table 2, Fig. 6). The EM2 TCR docked centrally onto HLA-B37-NP $\mathrm{N}_{338}$ with a $66^{\circ}$ angle (Fig. $6 \mathrm{~b}$ ), falling in the range previously observed for TCR-pHLA-I (average of $\left.63^{\circ}\right)^{50}$. The buried surface area (BSA) of the complex was of $\sim 1800 \AA^{2}$, also falling in the previously observed range for TCR-pHLA-I (average of $\left.1900 \AA^{2}\right)^{50}$ The EM2 TCR $a$-chain contributes to $40 \%$ of the contact surface (Fig. 6c), while the biased TRBV19+ $\beta$-chain contributes to $60 \%$ of the BSA, providing a direct basis for the TRBV19 bias observed in HLA-B37 ${ }^{+}$donors in response to $\mathrm{NP}_{338}$ and its variants. The peptide contributed to $25 \%$ of the pHLA BSA, with all six solventexposed residues contacted by the EM2 TCR. CDR2 $\beta$ (27\%), CDR3 $\alpha(23 \%)$, and CDR3 $\beta$ (20\%) are the highest contributors to the BSA, followed by CDR $1 \alpha$, CDR $2 \alpha$, and CDR $1 \beta$ (6-8\% each), as well as the framework (FW) residues of the $\beta$-chain (9\%) (Fig. 6c).

All of the CDR loops of the EM2 TCR contacted the HLA-B37 molecule (Fig. 6d), with the addition of two FW residues from the $\beta$-chain (Gln67 $\beta$ and Lys $83 \beta$ ). From the EM2 $\alpha$-chain, the CDR1/ 2 loops contributed to $\sim 10 \%$ of the TCR-HLA BSA and $16 \%$ for the CDR $3 \alpha$ (Supplementary Table 5 ). The CDR $1 / 2 \alpha$ loops made a contact with the region before the hinge of the HLA a2-helix (residue 151-158, Fig. 6f), while the CDR3a loop contacted the N-terminal part of the HLA a1-helix (residues 58 and 62, Fig. 6g). Within the $\beta$-chain, the CDR1 made only few contacts with the HLA ( $2 \%$ TCR-HLA BSA), and the contacts were driven by CDR2 $\beta$ (34\%), CDR3 $\beta$ (14\%), as well as FW $\beta$ (11\%) (Fig. 6d). The CDR3 $\beta$ loop contact with the HLA focused mostly on Gln155, which has its side chain sandwiched by the Tyr30a (CDR1 $\alpha$ ) and the ${ }^{110}$ SAMGT ${ }^{114}$ motif from the CDR3 $\beta$ loop (Supplementary Table 5, Fig. 6h). The FW residue Lys $83 \beta$ formed 


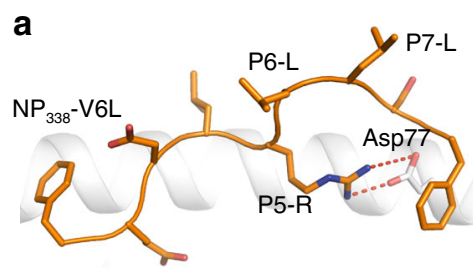

C
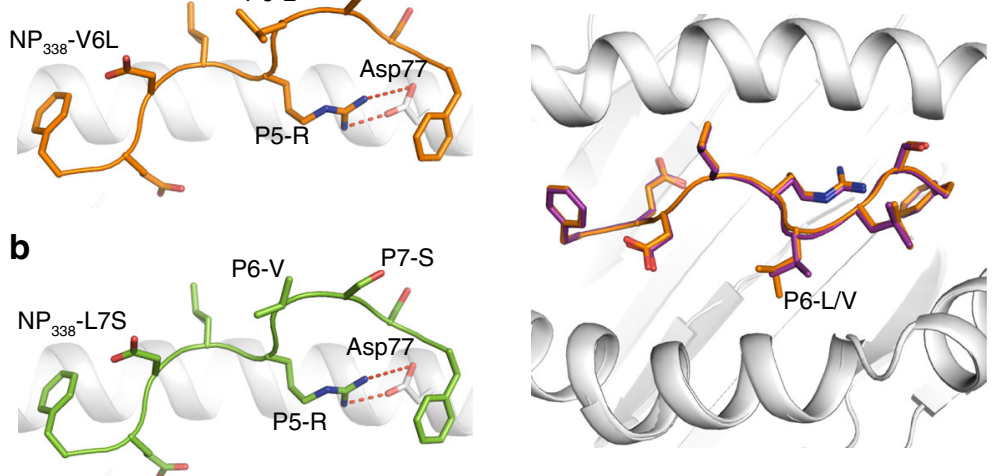

$\mathbf{e}$

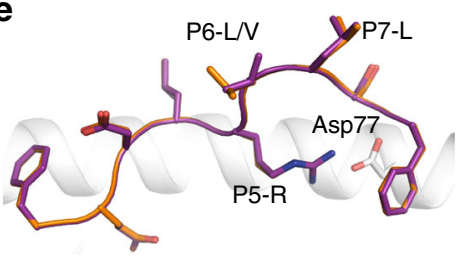

$\mathbf{f}$

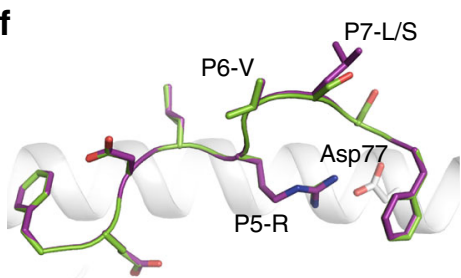

g

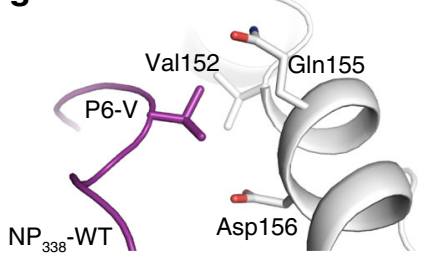

i
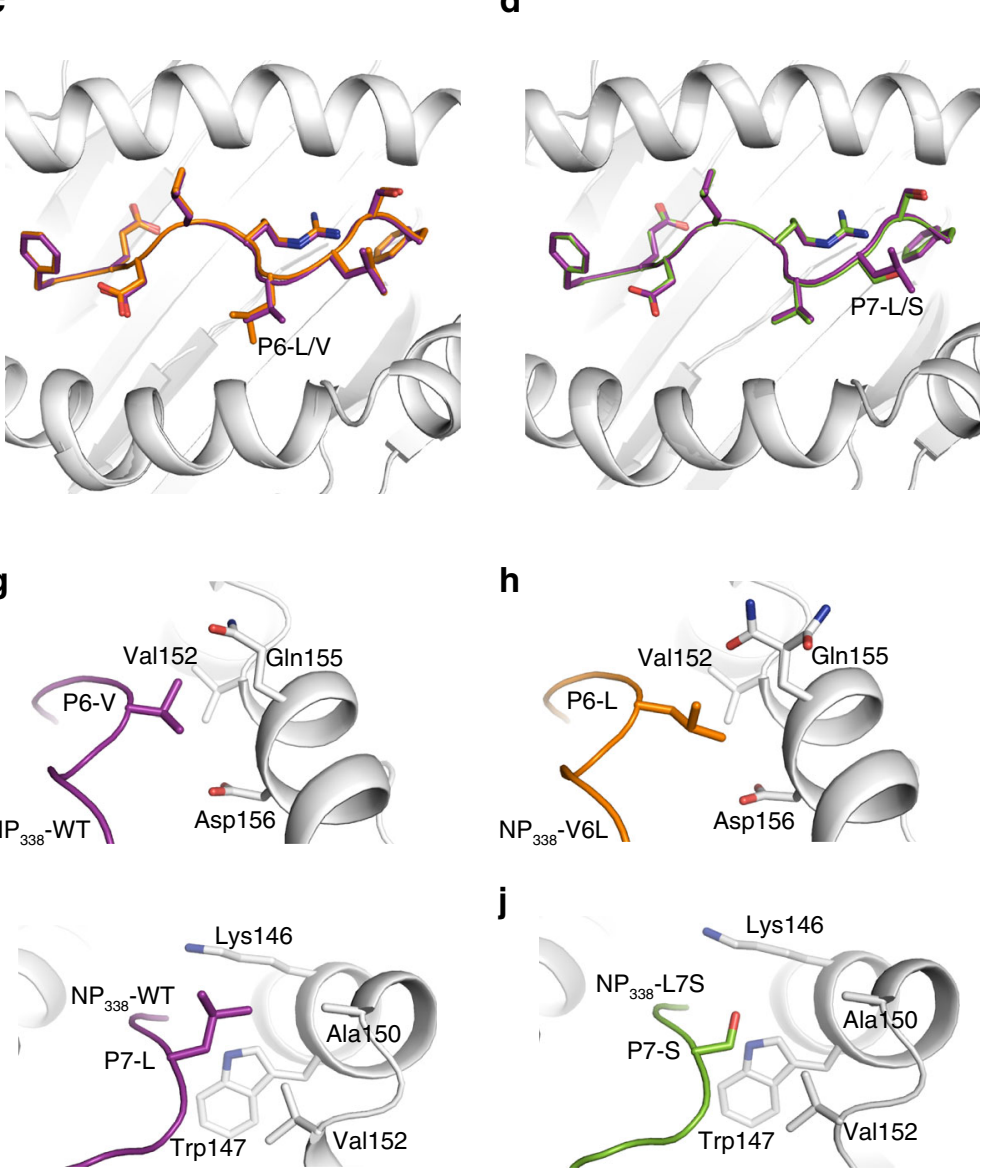

h

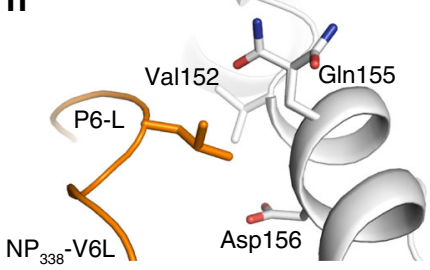

j

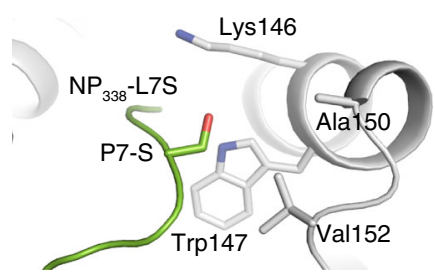

Fig. 3 Structures of HLA-B37 bound to $\mathrm{NP}_{338}$ and its two variants. Structure of the HLA-B37 (white cartoon) presenting either a NP $338^{-V 6 L}$ (orange) or $\mathbf{b}$ $\mathrm{NP}_{338^{-}}$L7S (green). c, d Top view or $\mathbf{e}, \mathbf{f}$ side view of the structural overlay of HLA-B37 (white cartoon) presenting the $\mathrm{NP}_{338}$ (purple) with either $\mathbf{c}_{\mathbf{1}} \mathbf{e} \mathrm{NP}_{338^{-}}$ $\mathrm{V} 6 \mathrm{~L}$ (orange) or $\mathbf{d}, \mathbf{e} \mathrm{NP}_{338}-\mathrm{L} 7 \mathrm{~S}$ (green). $\mathbf{g}-\mathbf{j}$ Zoomed in view on the HLA-B37 interaction with residue at position 6 ( $\mathbf{g}$, $\mathbf{h}$ ) and position 7 (i, $\left.\mathbf{j}\right)$ of the $N P_{338}$ (purple), $\mathrm{NP}_{338}-\mathrm{V} 6 \mathrm{~L}$ (orange) and $\mathrm{NP}_{338}-\mathrm{L} 7 \mathrm{~S}$ (green) peptides. The red dashed lines represent salt bridges between residues

a network of salt bridge with the HLA-B37 Glu76 and CDR1 $\beta$ Asp30, hovering above P8-Ser (Fig. 6i). The CDR2 $\beta$ loop form a hairpin loop that sat above the HLA a1-helix covering a large stretch of the HLA helix spanning from residue 65 to 79 (Fig. $6 \mathrm{~b}$, $\mathrm{d}, \mathrm{j}$ and Supplementary Table 5). The residue Gln67 $\beta$ from the FW, located downstream of the CDR2 $\beta$ loop was also contacting the $\alpha 1$-helix of the HLA-B37 molecule. Gln57 $\beta$, Asn60 $\beta$, Asp61 $\beta$, and Gln67 $\beta$ were forming a large hydrogen network with the HLA-B37 molecule.

Overall, CDR2 $\beta$ and FW $\beta$ make extensive interaction with the HLA-B37 molecule, providing a basis for the strong bias TRBV19 ${ }^{+}$ usage observed in the donors.

EM2 TCR contacts the $\mathrm{NP}_{338}$ peptide via a hydrophobic network. The peptide is predominantly contacted by CDR3 $\alpha(47 \%)$ and CDR $3 \beta(26 \%)$, as well as by CDR1 $\beta(17 \%)$ and CDR2 $\beta(10 \%)$ (Fig. 6b, e, Supplementary Table 5). The motif SGG within the CDR3 $a$ loop, with small or no side chain, allow the loop to be in close proximity and lodge itself between the side chains of P1-Phe and P3-Asp (Fig. 7a). The proximity of the loop allows the Gln113a to form hydrogen bonds with P3-Asp of the peptide and hydrophobic interaction with P4-Leu. Therefore, CDR3a loop forms a lid-like structure that covers the $\mathrm{N}$-terminal part of the peptide (Supplementary Table 5). Within the EM2 TCR $\beta$-chain, all the CDR loops were contacting the peptide $\mathrm{C}$-terminal section from residue P4-Leu to P8-Ser. P4-Leu was contacted by Gln57 $\beta$ from the CDR2 $\beta$ loop, while the CDR1 $\beta$ loop was interacting with both P7-Leu and P8-Ser that form a hydrogen bond with Asp30 $\beta$ (Supplementary Table 5). P6-Val and P7-Leu were both contacted by the CDR3 $\beta$ loop that sat on top of the central region of the peptide and form Van der Waals interaction. The ${ }^{109} \mathrm{MSAM}^{112}$ motif from the CDR3 $\beta$ loop could hover on the central part of the peptide due to the small side chains of the ${ }^{110} \mathrm{SA}^{111}$ residues. The CDR3 $\beta$ loop was thus making contacts with P6-P7 residues of the peptide mainly via Van der Waals bonds (Supplementary Table 5).

Interestingly, the comparison of HLA-B37-NP 338 in its free and liganded state with the EM2 TCR revealed that the peptide (r.m.s. d. of $0.2 \AA$ ) and HLA-B37 (r.m.s.d. of $0.3 \AA$ ) did not change conformation upon TCR binding (Fig. 7c). The hydrophobic nature of the interaction between the EM2 TCR and the $\mathrm{NP}_{338}$ peptide is complementary with the conformation of the $\mathrm{NP}_{338}$ peptide bound to HLA-B37 that presents only the hydrophobic residue to the TCR. This might explain the lack of response for $\mathrm{NP}_{338}$ when presented by both HLA-B18 and HLA-B44 molecules, in which the peptide presents its charged P5-Arg to the TCR (Fig. 1b, c).

Altogether, the structure of the EM2 TCR-HLA-B37-NP 338 complex revealed that the TCR is using hydrophobic interaction from its CDR3 loops to engage with the all stretch of the $\mathrm{NP}_{338}$ peptide.

EM2 TCR affinity for $\mathrm{NP}_{388^{-}} \mathrm{V} 6 \mathrm{~L}$ is higher than for $\mathrm{NP}_{388}-\mathrm{WT}$. We next evaluated the ability of the EM2 TCR to recognize the $\mathrm{NP}_{338}$ and its two major variants $\left(\mathrm{NP}_{338^{-}}\right.$V6L and $\left.\mathrm{NP}_{338^{-L}} \mathrm{LS}\right)$ 
a

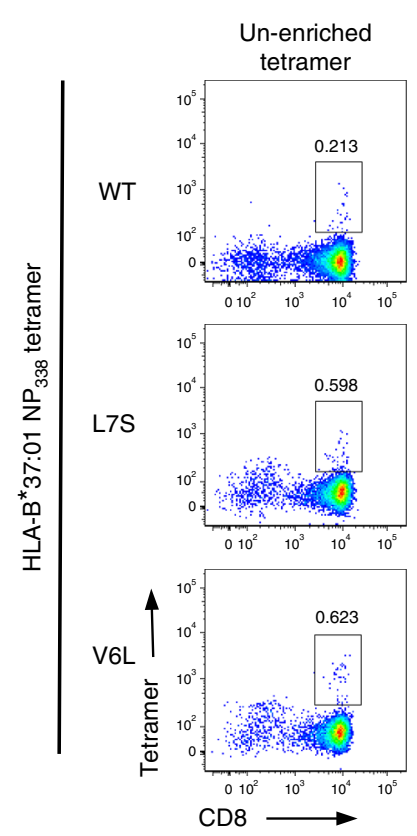

Donor 2
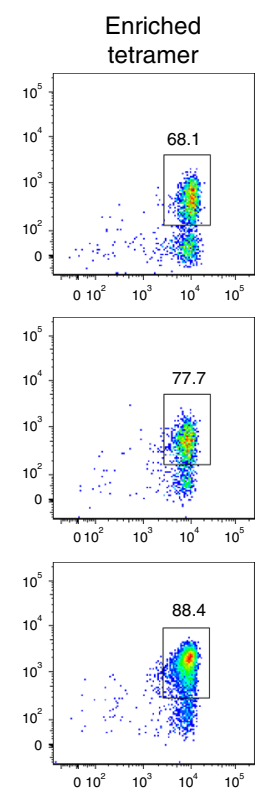

b

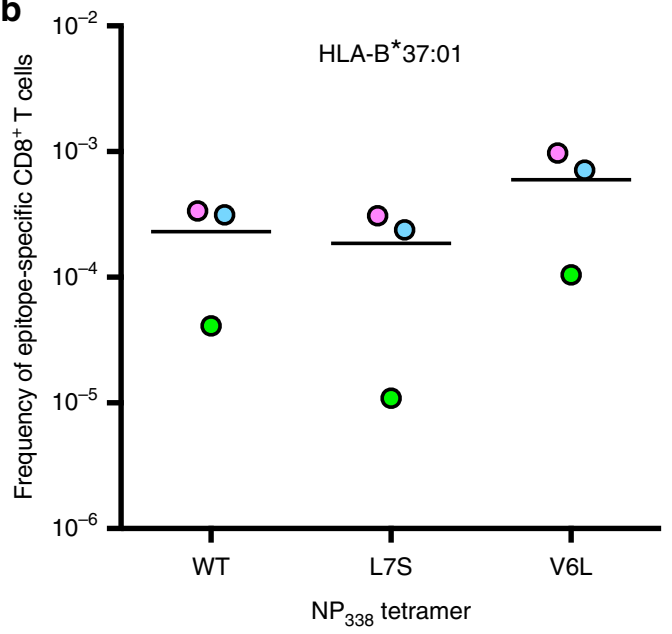

Donor 1

Donor 3
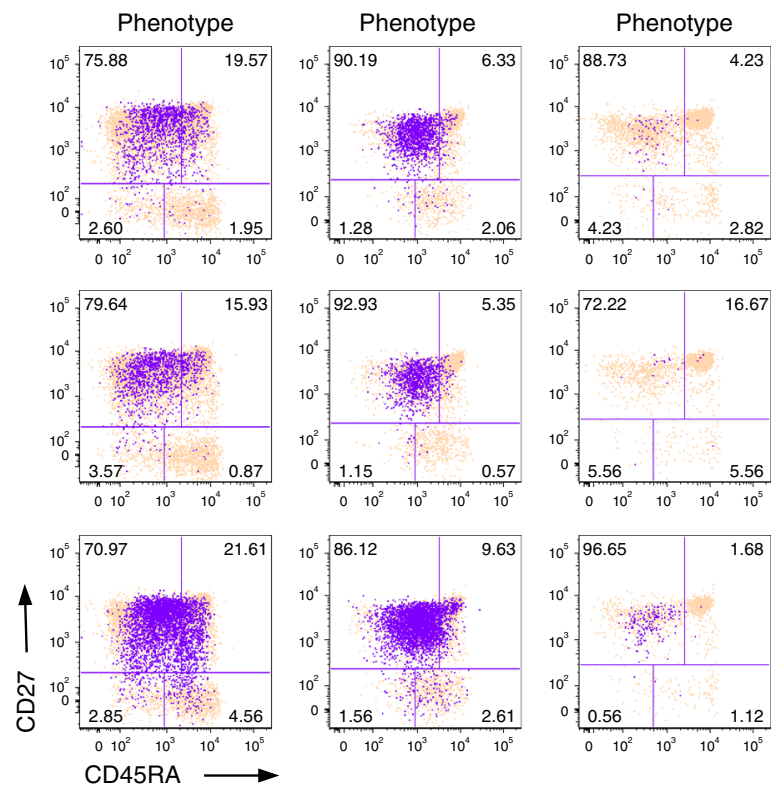

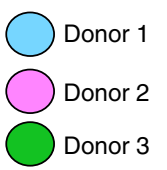

Fig. $4 \mathrm{HLA}-\mathrm{B} 37^{+} \mathrm{NP}_{338}$-specific $\mathrm{CD} 8^{+} \mathrm{T}$ cells recognize $\mathrm{NP}_{338}$ variants directly ex vivo. PBMCs from $\mathrm{HLA} \mathrm{B}^{\star 37}: 01^{+}$donors $(n=3)$ were tetramer stained

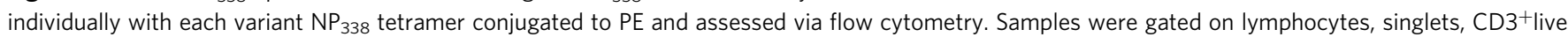
${ }^{+}$dump ${ }^{-}$cells; as per Supplementary Figure 2c. a Representative dot plots of tetramer staining of CD3+ cells prior to and following enrichment (numbers respond to a proportion of tetramer ${ }^{+}$of $\mathrm{CD}^{+}{ }^{+} \mathrm{T}$ cells) and CD27/CD45RA phenotype of tetramer ${ }^{+} \mathrm{CD}^{+} \mathrm{T}^{+}$cells (purple) superimposed on unenriched $\mathrm{CD}^{+} \mathrm{T}$ cells. $\mathbf{b}$ Frequency of $\mathrm{NP}_{338}$ variant-specific $\mathrm{CD} 8^{+} \mathrm{T}$ cells in $\mathrm{HLA}-\mathrm{B}^{\star} 37: 01^{+}$donors

using surface plasmon resonance (Fig. 7d-f; Supplementary Table 6). The EM2 TCR bound to the HLA-B37-NP 338 complex with a $K_{\mathrm{d}}$ of $\sim 130 \mu \mathrm{M}$ (Fig. $7 \mathrm{~d}$ ), displaying a low affinity for an antiviral CD8 ${ }^{+} \mathrm{T}$ cell, the average being $35 \mu \mathrm{M}^{50}$. The EM2 TCR bound to $\mathrm{NP}_{338}$-L7S with a similar affinity to the one observed for the $\mathrm{NP}_{338}$ bound to HLA-B37 $\left(K_{\mathrm{d}} \sim 150 \mu \mathrm{M}\right.$, Fig. $\left.7 \mathrm{e}\right)$. Interestingly, the EM2 TCR affinity was increased by four-fold for the $\mathrm{NP}_{338}$-V6L $\left(K_{\mathrm{d}} \sim 30 \mu \mathrm{M}\right.$, Fig. $\left.7 \mathrm{f}\right)$ compared to $\mathrm{NP}_{338}$ when bound to HLA-B37.

The structures of each $\mathrm{NP}_{338}$ and variants in complex with the HLA-B37 molecule (Fig. 3, Supplementary Table 2) allowed us to understand the impact of the $\mathrm{NP}_{338}$ mutation onto the EM2 TCR recognition. Overlay of the HLA-B37- $\mathrm{NP}_{338}$-L7S with the EM2 TCR-HLA-B37-NP 338 structures showed that the smaller P7-Ser would be readily accommodated by the EM2 TCR without structural changes (Fig. 7g). This might explain the similar affinity observed for the EM2 TCR towards both peptides $\left(\mathrm{K}_{\mathrm{d}} \sim\right.$ $130-150 \mu \mathrm{M})$. In a similar fashion, an overlay of the HLA-B37$\mathrm{NP}_{338}$-V6L with the EM2 TCR-HLA-B37-NP 338 structures (Fig. 7h) shows that the larger side chain of the P7-Leu might create additional contact with the CDR3 $\beta$ loop and might in turn provide a basis for the improved affinity observed for the EM2 TCR towards the HLA-B37-NP $338^{-V 6 L}\left(K_{\mathrm{d}} \sim 30 \mu \mathrm{M}\right)$.

Thus our data demonstrate that $\mathrm{CD}^{+} \mathrm{T}$ cell cross-reactivity in the context of $\mathrm{NP}_{338}$ peptide and its variants is favored by similar conformations adopted by the epitopes.

Key TCRs are cross-reactive towards $\mathrm{A1}-\mathrm{NP}_{44}$ variants. To investigate whether cross-reactivity and thus protection against distinct IAV strains is $\mathrm{NP}_{338}$-specific or occurs towards other IAV-specific epitopes, we assessed CD8 ${ }^{+} \mathrm{T}$ cell responses towards 
a
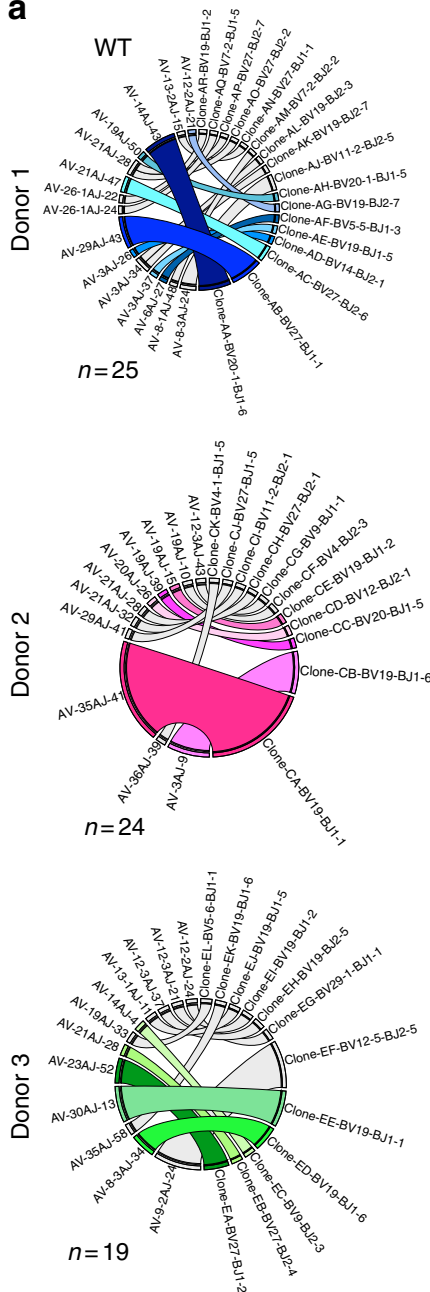

$\mathrm{CDR} 3 \alpha / \mathrm{CDR} 3 \beta$

TRAV14:CAMRGSGMNNDMRF / TRBV20:CSARAYRGYNSPLHF TRAV29:CAARGGNDMRF / TRBV27:CASSLTGQGAFF TRAV21:CAAPLEYGNKLVF / TRBV27:CASGRLVTGGGTGANVLTF TRAV3:CAVRLTRDNYGQNFVF / TRBV14:CASSQVDYNEQFF TRAV3:CAVRDSASGNTGKLIF / TRBV19:CASSWGTGGNOPQH TRAV6:CAHVNTNAGKSTF / TRBV5:CASSGLINGNTIYF TRAV12:CAVKGRYNFNKFYF / TRBV19:CASSVGTGAYEQYF TRAV19:CALSNAKTSYDKVIF/ TRBV20:CSARPGOFYSNOPOH TRAV17:CATDFALSSGGGADGLTF / TRBV3:CASSLTGHNQPQHF

TRAV35:CAGRNMNSGYALNF / TRBV19:CASSIGVRAFF TRAVI:CAVSYTGGGYF/TRBV19:CASSMAQGARSPLHF TRAV3:CAVSYTGGFKTIF / TRBV19: CASSMAQGARSPLHF
TRAV19:CALSAHRFENAGNMLTF / TRBV20: CSARDGQVYSNQPQHF TRAV19:CALSAHRFENAGNMLTF/TRBV20: CSARDGQVYSNQP TRAV19:CALSAGGLDQAGTALIF / TRBV19:CASSMGRDGYTF

TRAV23:CAATYTAGGTSYGKLTF / TRBV27:CASTNYAGGDRGYTF TRAV23:CAATYTAGGTSYGKLTF / TRBV27:CASTNYAGGD TRAV21:CAGLRGAGSYQLTF/ TRBV27:CASSATKNIQYFG TRAV14:CAMREVSGGYNKLIF / TRBV9:CASSVVATGGRGTDTQYF TRAV8:CAVGARETYNTDKLIF / TRBV19:CASSPRQGNNSPLHF TRAV30:CGTERSGGYQKVTF TRBV19:CASSMSAMGTEAFF Variant-specific clonotype
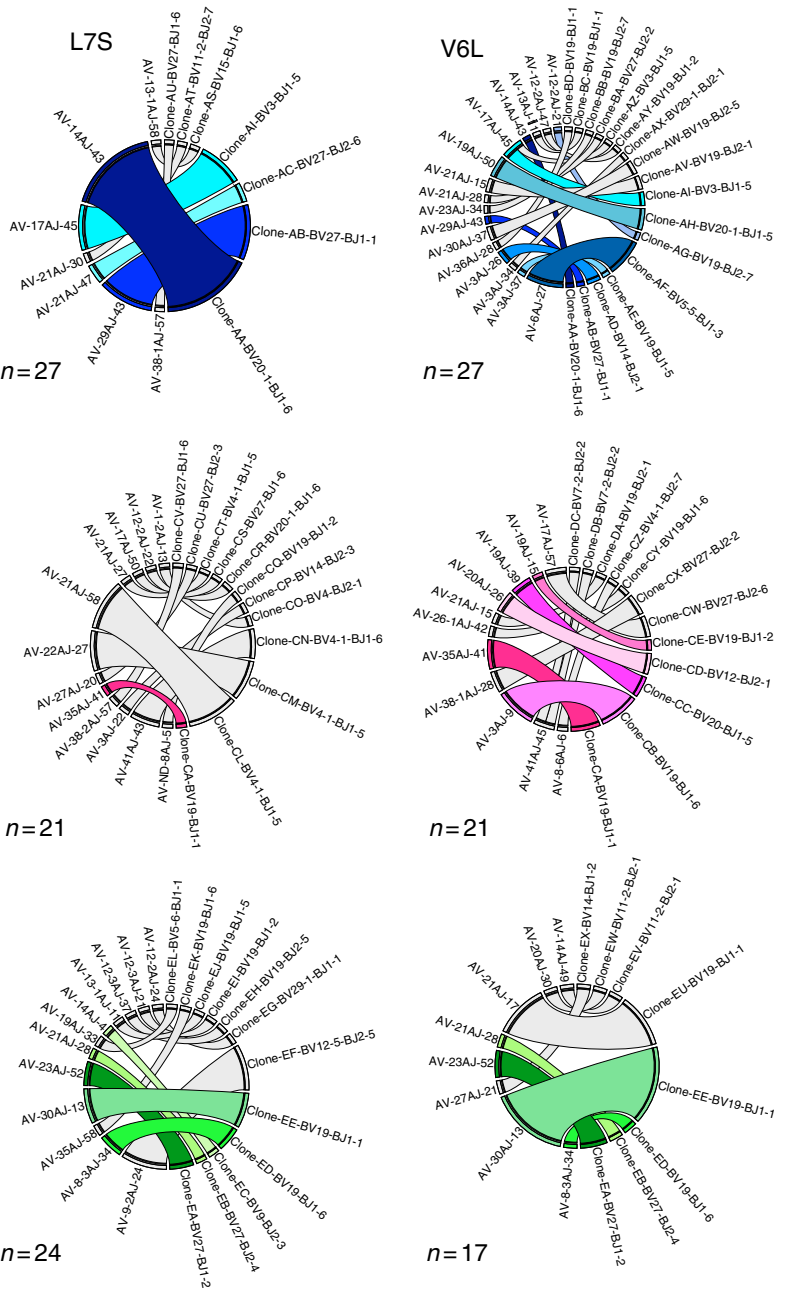

C b $\quad$ HLA-B*37:01 $\mathrm{NP}_{338}$ Tetramer

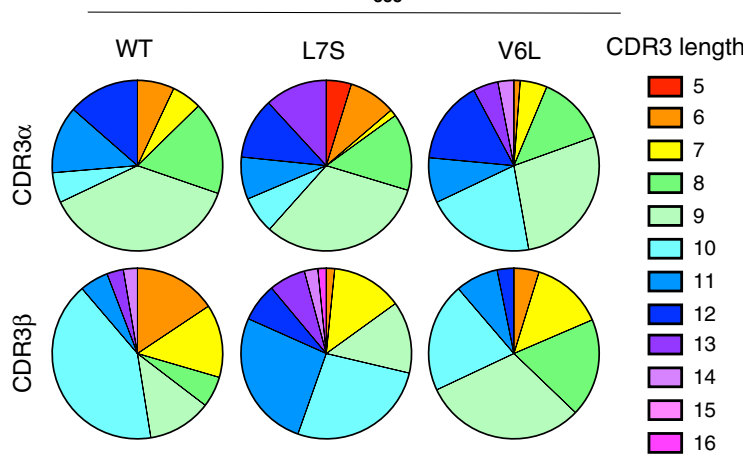

\begin{tabular}{|c|c|c|c|c|c|c|c|}
\hline CDR3 & Variant & $\begin{array}{c}\text { Preferential } \\
\text { length(s) }\end{array}$ & Frequency & CDR3 & Variant & $\begin{array}{l}\text { Preferential } \\
\text { length(s) }\end{array}$ & Frequency \\
\hline \multirow{4}{*}{$\operatorname{CDR} 3 \alpha$} & WT & 9 & $37.67 \pm 11.24$ & \multirow{4}{*}{ CDR3 $\beta$} & WT & 10 & $41.27 \pm 23.37$ \\
\hline & L7S & 9 & $31.93 \pm 14.48$ & & L7S & 10 & $26.71 \pm 23.19$ \\
\hline & & & & & & 11 & $26.28 \pm 35.05$ \\
\hline & V6L & 9 & $27.7 \pm 16.77$ & & V6L & 9 & $30.83 \pm 14.48$ \\
\hline
\end{tabular}

Fig. 5 Key TCRs cross-recognize $\mathrm{NP}_{338}$ variant peptides directly ex vivo. PBMCs from HLA-B*37:01+ donors (Donors 1-3) were tetramer stained individually with each of the $\mathrm{NP}_{338}$ tetramers conjugated to $\mathrm{PE}$, enriched, and single-cell sorted on lymphocytes, singlets, $\mathrm{CD} 3^{+}$live ${ }^{+}$dump ${ }^{-}$cells, $\mathrm{CD}{ }^{+}{ }^{+}$tet + cells; as per Supplementary Figure 2c. The TCR $\alpha \beta$ repertoire was determined using a multiplex RT-PCR. a Graphical representation of the TCR $\alpha \beta$ repertoire used by each of three donors for the recognition of variant $\mathrm{NP}_{338}$ peptides. $\mathbf{b}$ Average $C D R 3 \alpha$ and $C D R 3 \beta$ length used for the recognition of $\mathrm{NP}_{338}$ from HLA-B ${ }^{\star} 37: 01^{+}$donors. c Preferred CDR3 $\alpha$ and CDR3 $\beta$ length of $\mathrm{NP}_{338}$-specific cells isolated from HLA-B*37:01+ donors in the recognition of variant $\mathrm{NP}_{338}$ peptides 
a

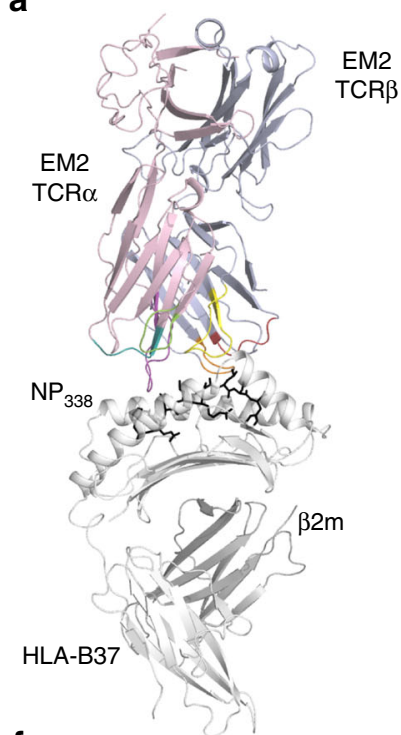

f

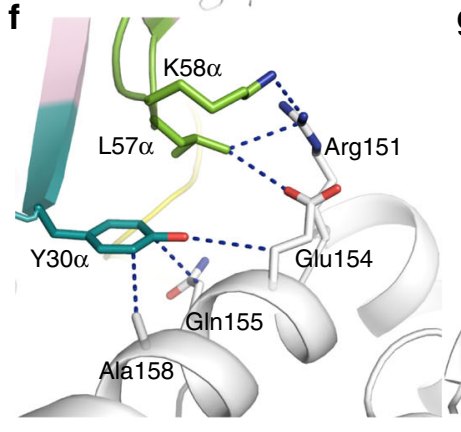

i

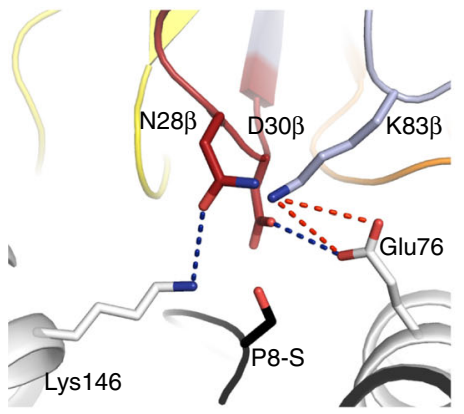

b

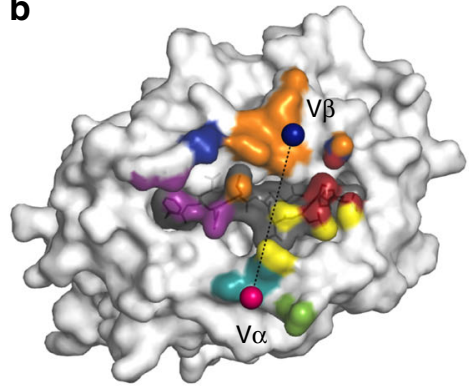

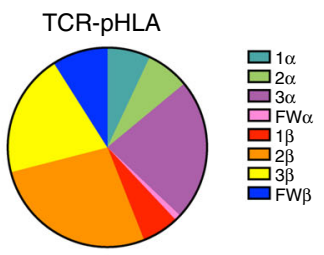

d

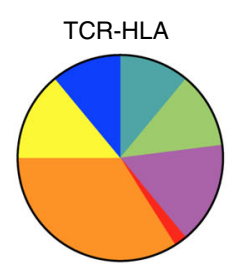

e TCR-peptide

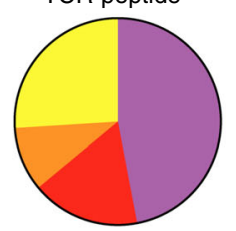

g

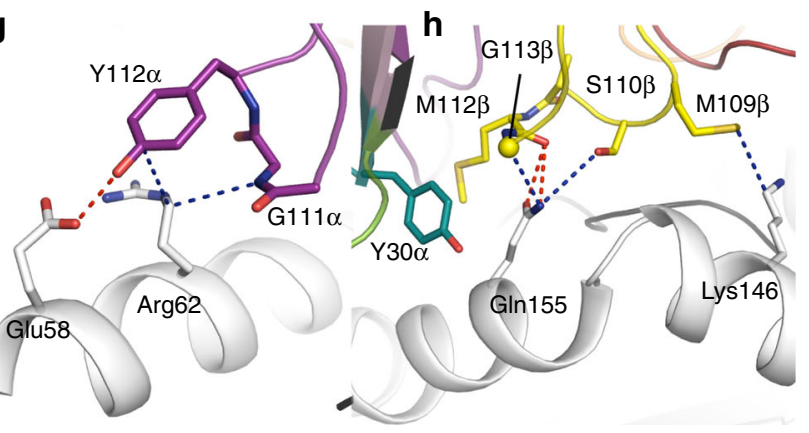

j

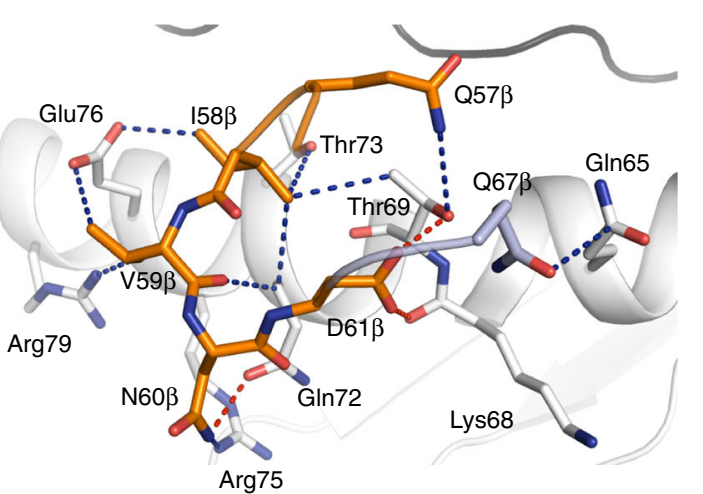

Fig. 6 Structure of EM2 TCR in complex with the HLA-B37-NP 338 . a Overview of the EM2 TCR ( $\alpha$-chain in pink and $\beta$-chain in blue) bound to the HLA-B37$\mathrm{NP}_{338}$ complex (HLA in white and peptide in black). b The EM2 TCR-binding footprint on the HLA-B37 surface (white) and NP 338 peptide (gray surface) is represented by the atomic contact made by each TCR residues colored in teal, green, and purple for the CDR1, 2, and 3 of the $\alpha$-chain; red, orange, and yellow for the CDR1, 2, and 3 of the $\beta$-chain; and pink and blue when contacted by the framework residue of the $\alpha$ - and $\beta$-chain, respectively. The pie charts represent the buried surface area at the interface between $\mathbf{c}$ the TCR with the HLA-B37-NP 338 or with $\mathbf{d}$ HLA-B37 alone or e with the peptide alone. The different colors represent the TCR gene segment as per $\mathbf{b}$. Interaction of the EM2 TCR with the HLA-B37 molecule (white) are represented for $\mathbf{f}$ CDR1 $\alpha$ and CDR2 $\alpha ; \mathbf{g}$ CDR3 $\alpha ; \boldsymbol{h}$ CDR3 $\beta ; \mathbf{i} C D R 1 \beta$ and FW $\beta$; and $\mathbf{j}$ for CDR2 $\beta$. The same color scheme is used as per $\mathbf{b}$ for the different segments of the TCR. The sphere represents the $\mathrm{C} \alpha$ atom of glycine residue, the blue dashed lines represent hydrophobic interaction, while the red dashed lines indicated hydrogen bond or salt bridges

the HLA-A1-restricted $\mathrm{NP}_{44}$ peptide (Fig. 8). Conservation analysis revealed that there were two major variants of the peptide, the CTELKLSDY $\left(\mathrm{NP}_{44}\right)$ and the S7N mutant CTELKLNDY $\left(\mathrm{NP}_{44}-\mathrm{S} 7 \mathrm{~N}\right)$, covering $34-100 \%$ of $\mathrm{H} 3 \mathrm{~N} 2, \mathrm{H} 7 \mathrm{~N} 9, \mathrm{H} 5 \mathrm{~N} 1$, and H1N1 virus strains (Supplementary Table 7). To investigate cross-reactivity towards these variant $\mathrm{NP}_{44}$ peptides, PBMCs from healthy HLA-A $1^{+}$donors $(n=3)$ were tetramer stained with each of the $\mathrm{NP}_{44}$ variants directly ex vivo and magnetically enriched and single-cell sorted (Fig. 8a). The TCRaß repertoire was then determined using multiplex RT-PCR (Fig. 8b). Two of the three donors (Donors 1 and 20 ) had both $\mathrm{NP}_{44^{-}}$and $\mathrm{NP}_{44^{-}}$ S7N-specific $\mathrm{CD}^{+} \mathrm{T}$ cell populations. Interestingly, Donor 21 had only a $\mathrm{NP}_{44}$-specific $\mathrm{CD}{ }^{+} \mathrm{T}$ cell population, with no detectable S7N-specific $\mathrm{CD}^{+} \mathrm{T}$ cell population (Fig. 8b). A predominant TRAV8-2 ${ }^{+}$TCR $a$ chain expressing a CDR3a sequence CVVSDRNFNKFYF paired with multiple distinct TCR $\beta$ s and was detected in two out of three donors (Supplementary Table 8). Similar to the $\mathrm{NP}_{338}$ system, specific clonotypes 
a

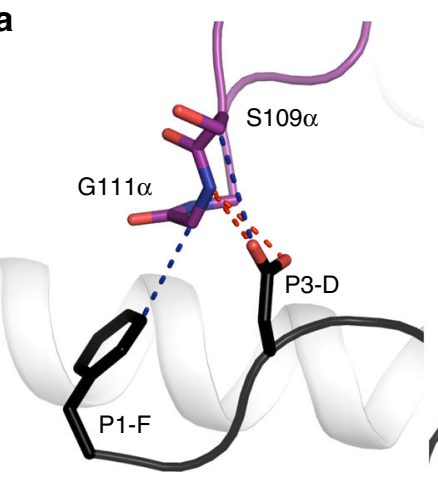

d

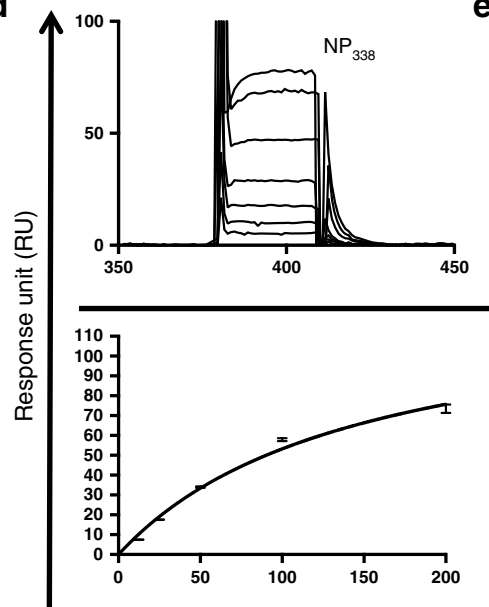

b

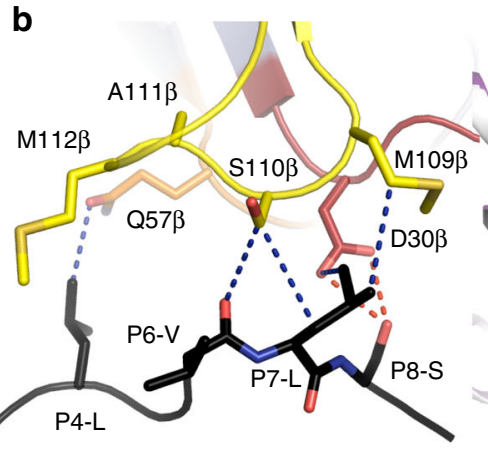

c

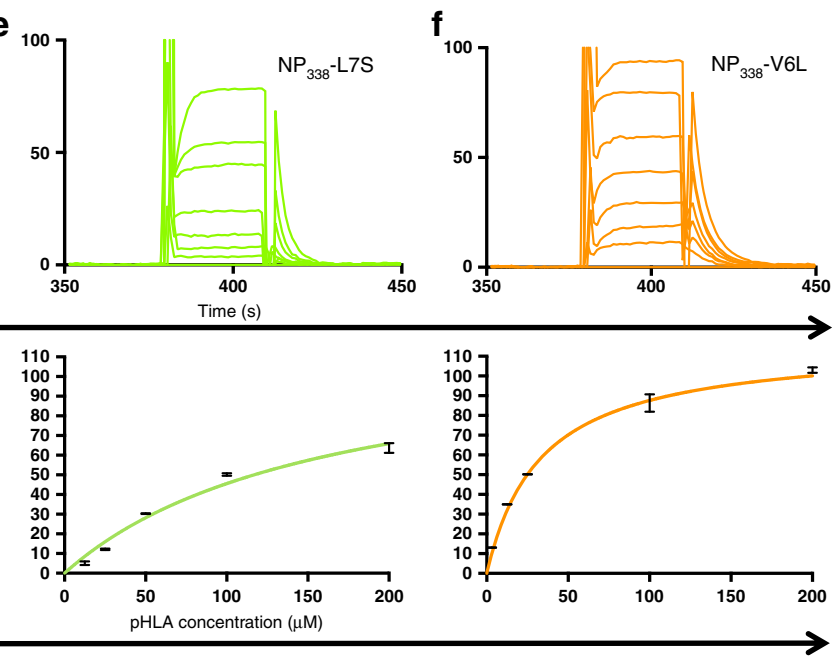

g

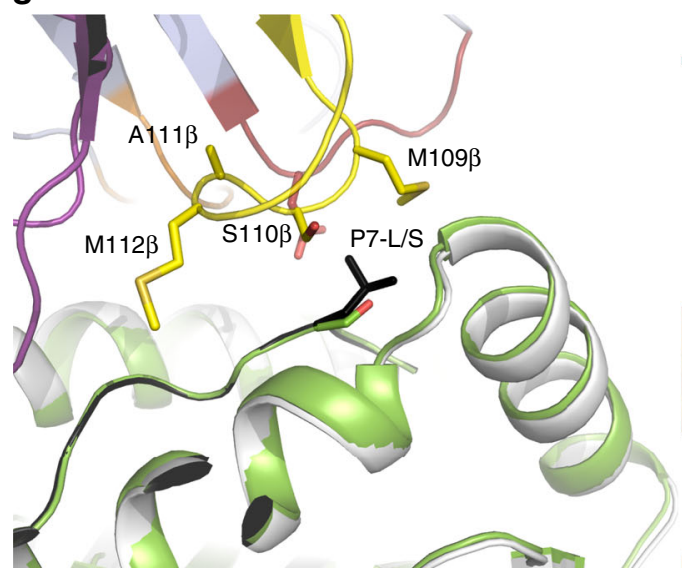

h

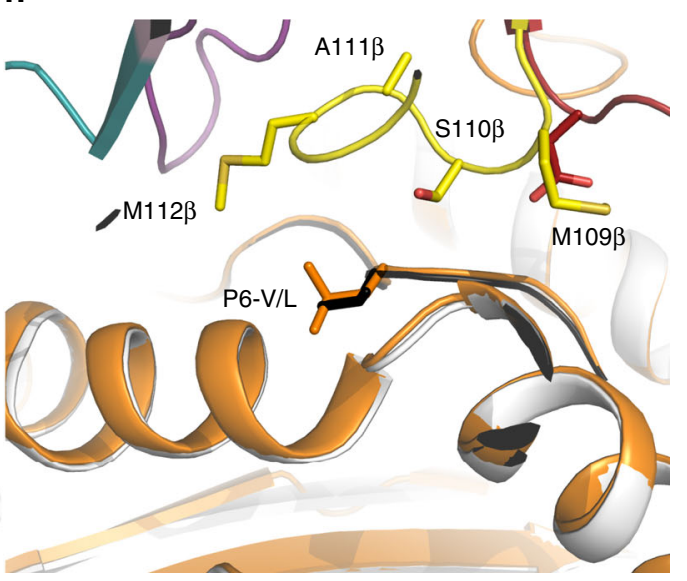

Fig. 7 EM2 TCR recognizes the structurally similar $\mathrm{NP}_{338}$ variants. a Interaction between the EM2 TCR CDR3 loop (purple) with the NP 338 peptide (black). b Interaction of the $\mathrm{NP}_{338}$ peptide (black) with the CDR1 $\beta$ (red), CDR2 $\beta$ (orange), and the CDR3 $\beta$ loops (yellow). The blue and red dashed lines indicate Van der Waals or hydrogen bonds, respectively. c Top view of the structural overlay of the HLA-B37-NP 338 free (purple) or bound to the EM2 TCR (white for HLA and black for the peptide). d-f Surface plasmon resonance sensorgrams (top panel) and equilibrium binding curves (bottom panel) of the EM2 TCR for the HLA-B37 presenting the $\mathrm{NP}_{338}$ (d, in black), $\mathrm{NP}_{338}-\mathrm{L} 7 \mathrm{~S}$ (e, in green), or $\mathrm{NP}_{338} \mathrm{V6L}$ (f, in orange). The experiment was done twice in duplicate. g Overlay of the EM2 TCR-HLA-B37-NP 338 (HLA in white and peptide in black) with the HLA-B37-NP $338-\mathrm{L} 7 \mathrm{~S}$ (green) structures. The EM2 TCR is colored as per Fig. 6 , with the CDR3 $\beta$ loop in yellow. $\mathbf{h}$ Overlay of the EM2 TCR-HLA-B37-NP 338 (HLA in white and peptide in black) with the HLA-B37-NP $338^{-V 6 L}$ (orange) structures

isolated from Donor 1 could recognize both $\mathrm{NP}_{44}$ variants, while the remainder of the repertoire was variant specific (Fig. 8b). Interestingly, the TCRa $\beta$ repertoire of Donor 20 was entirely $\mathrm{NP}_{44}$ variant specific. We previously solved the structures of both $\mathrm{NP}_{44}$ and $\mathrm{NP}_{44}-\mathrm{S} 7 \mathrm{~N}$ peptides in complex with the HLA-A1 molecule ${ }^{23}$. In similar fashion as HLA-B37 and the $\mathrm{NP}_{338}$ variants, the $\mathrm{NP}_{44}$ variants adopted similar conformation in the cleft of HLA-A1 molecule. This suggests that here too molecular similarity might underpin $\mathrm{CD}^{+}{ }^{+} \mathrm{T}$ cell cross-reactivity and favor the recognition of multiple IAV strains.

Overall, these data show that TCR $\alpha \beta$ cross-reactivity is not limited to the recognition of HLA-B37- $\mathrm{NP}_{338}$ and highlight the importance of cross-reactive $\mathrm{CD}^{+} \mathrm{T}$ cells in the recognition of virus-infected cells and thus their potential to protect against distinct IAV strains. 

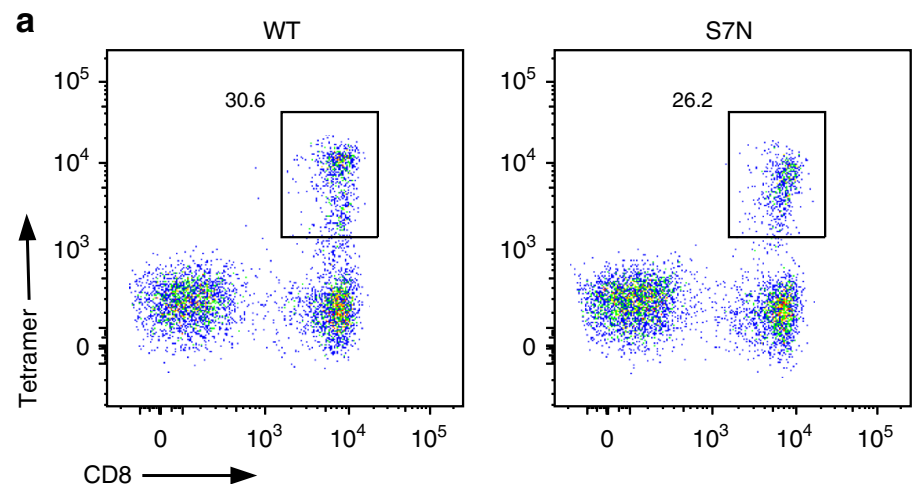

b
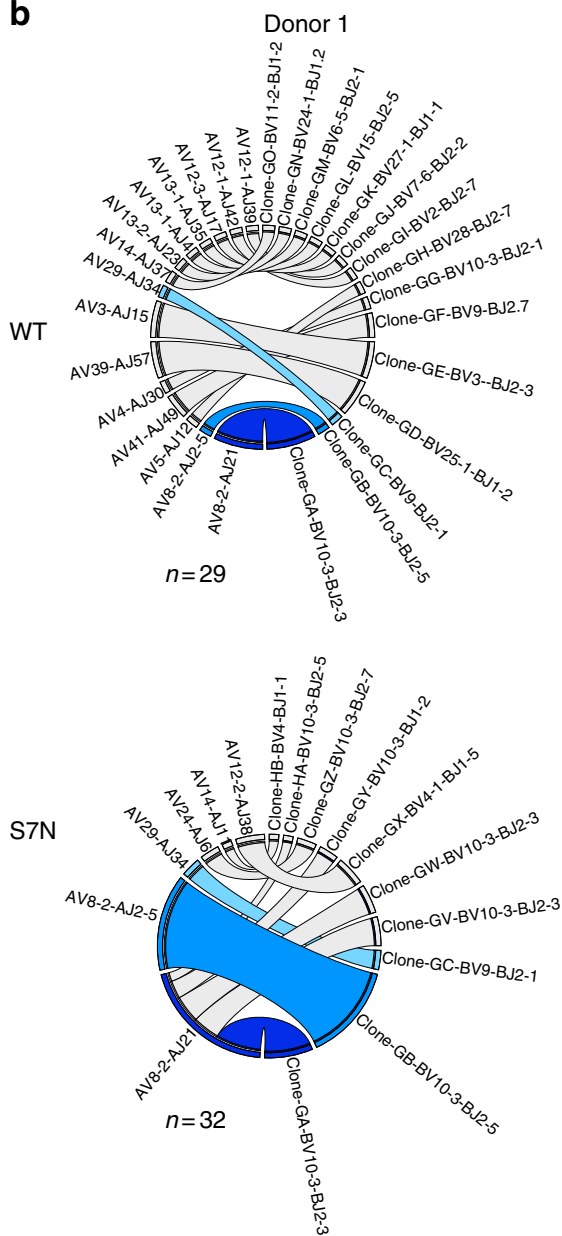

RAV8-2:CVVSDRNFNKFYF/TRBV10-3:CAISESNGADTQYF

TRAV8-2:CVVSDRNFNKFYF/TRBV10-3:CAISESQGPGGETQYF

TRAV29:CAASGRTDKLIF/TRBV9:CASSVESSGSPYQFF

Variant-specific clonotype
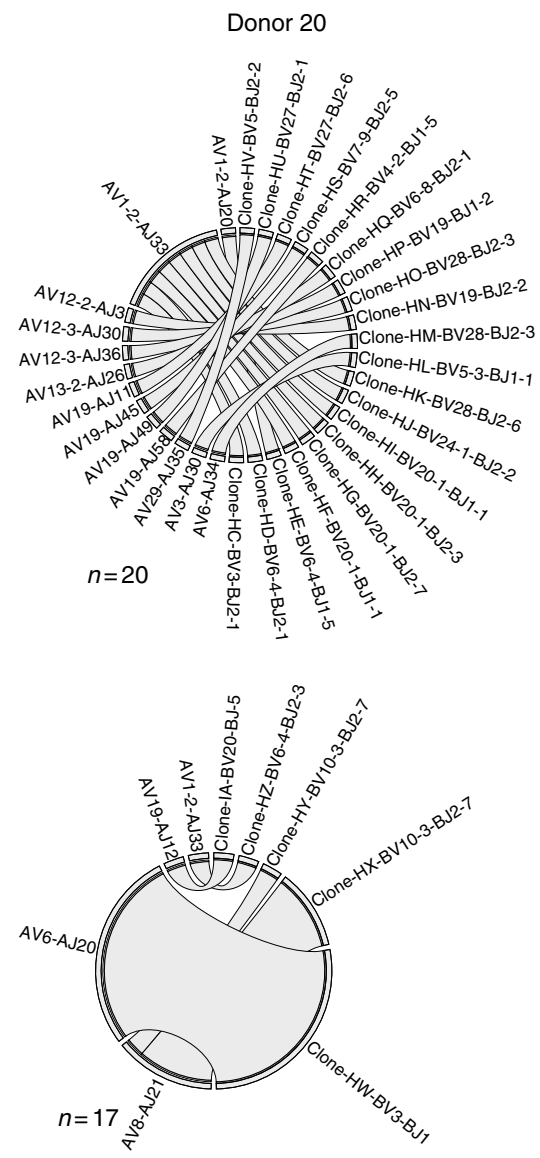

Donor 21

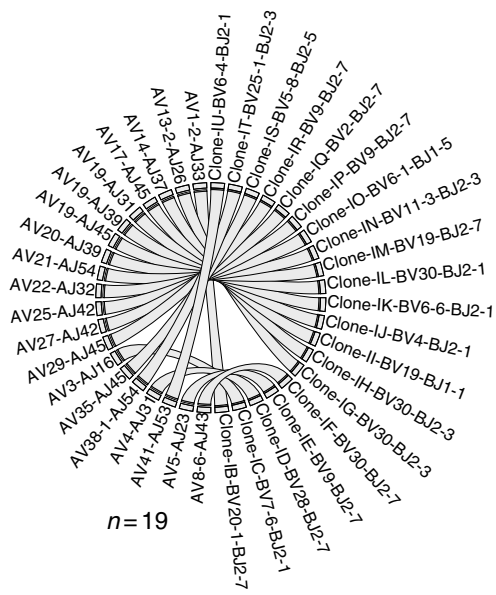

No $\mathrm{NP}_{44}-\mathrm{S} 7 \mathrm{~N}$

population

Fig. 8 TCR $\alpha \beta$ clonotypes can recognize HLA-A*01:01-restricted $N P_{44}$ variants. PBMCs from HLA-A*01:01+ donors (Donors 1, 20 and 21 ) were tetramer stained individually with each of the $\mathrm{NP}_{44}$ tetramers conjugated to PE. Samples were enriched, surface stained, and single-cell sorted on lymphocytes, singlets, CD3+live ${ }^{+}$dump ${ }^{-}$cells, CD8 ${ }^{+}$tet $^{+}$cells, as per Supplementary Figure 2c, and the TCR $\alpha \beta$ repertoire was determined using a multiplex RT-PCR. a Representative dot plots of $\mathrm{NP}_{44}$ tetramer staining of $\mathrm{CD}^{+}{ }^{+} \mathrm{T}$ cells following magnetic enrichment. Numbers are represented as a proportion of tetramer ${ }^{+}$ of $\mathrm{CD}^{+} \mathrm{T}$ cells. $\mathbf{b}$ Summary of the TCR $\alpha \beta$ repertoire used by each of the three donors for the recognition of the variant $\mathrm{NP}_{44}$ peptides

\section{Discussion}

There is great interest in the development of a universal CD8 ${ }^{+} \mathrm{T}$ cell-mediated vaccine towards IAV. However, to realize this, first a thorough understanding of prominent human influenza-specific $\mathrm{CD}^{+} \mathrm{T}$ cell epitopes is needed. We have previously shown that NP is the most immunogenic antigen in both HLA- $A^{\star} 02: 01$-positive ${ }^{51}$ and -negative individuals ${ }^{39}$. However, as the conservation of the known influenza epitopes varies between $16 \%$ and 56\%, depending on ethnicity ${ }^{23}$, understanding inter-epitope cross-recognition across diverse IAV strains is needed. In this study, we have used the variable $\mathrm{NP}_{338}$ and $\mathrm{NP}_{44}$ peptides to dissect CD8 ${ }^{+} \mathrm{T}$ cell recognition of different peptide variants and thus distinct IAV strains. 
$\mathrm{NP}_{338}$ has two major variant peptides, covering $~ 93 \%\left(\mathrm{NP}_{338^{-}}\right.$ $\mathrm{L} 7 \mathrm{~S})$ and $\sim 96 \%\left(\mathrm{NP}_{338}-\mathrm{V} 6 \mathrm{~L}\right)$ of $\mathrm{H} 1 \mathrm{~N} 1$ and $\mathrm{H} 3 \mathrm{~N} 2$ viruses, respectively. Although $\mathrm{CD} 8^{+} \mathrm{T}$ cell responses are highly peptide specific $^{34}$, they can tolerate variations within $\mathrm{CD}^{+}{ }^{+} \mathrm{T}$ cell peptides $^{22,29,30,34}$. We identified functional cross-reactivity towards the variant $\mathrm{NP}_{338}$ peptides, albeit to different levels. Using a multiplex RT-PCR for the detection of the TCR $\alpha \beta$ repertoire directly ex vivo, we confirmed that $\mathrm{CD} 8^{+} \mathrm{T}$ cells were cross-reactive towards these distinct $\mathrm{NP}_{338}$ variants, at a clonotypic level, with $\sim 55 \% \mathrm{TCR} \alpha \beta$ repertoire being capable of recognizing multiple $\mathrm{NP}_{338}$ variants. Interestingly, unique clonotypes with distinct TRAV-TRBV pairings in each individual recognized all three $\mathrm{NP}_{338}$ variants. Furthermore, this crossreactivity was increased following in vitro amplification, potentially suggesting that activation increases expansion of crossreactive clones, allowing certain TCR $\alpha \beta$ clonotypes to recognize distinct viral variants and potentially prevent viral escape. Additionally, we showed that the importance of cross-reactive TCRa $\beta$ repertoires is not limited to the recognition of $\mathrm{NP}_{338}$ and that cross-reactive $\mathrm{CD}^{+}$TCR $\alpha \beta$ can recognize HLA-A1restricted $\mathrm{NP}_{44}$ variant peptides.

To understand the molecular basis of cross-reactive TCR $\alpha \beta$ recognition, we solved the structure of $\mathrm{NP}_{338}$ and its variants bound to the HLA-B37 molecule, as well as the structure of a cross-reactive TCR in complex with HLA-B37-NP 338 . First, our data show that the two $\mathrm{NP}_{338}$ variants were structural mimics of the WT peptide. Second, the $\mathrm{NP}_{338}$ peptide conformation was not altered by TCR engagement, and therefore the conserved structure of the $\mathrm{NP}_{338}$ variants favored TCR cross-reactivity, a mechanism that is thought to underpin cross-reactivity and alloreactivity more broadly $45,52,53$. The structures also demonstrated that only HLA-B37, and not HLA-B18 nor HLA-B44, binds the $\mathrm{NP}_{338}$ with a secondary anchor residue (P5-Arg), revealing the hydrophobic surface of the $\mathrm{NP}_{338}$ peptide, which might help cross-reactivity ${ }^{36,54}$. This hydrophobic surface of the $\mathrm{NP}_{338}$ was disrupted when the peptide was presented by HLAB44 or HLA-B18 molecules, which exposed the charged P5-Arg, and for which no $\mathrm{T}$ cell recognition was observed.

Together, these data imply that HLA-B $37^{+}$donors may have a level of protection against $\mathrm{H} 1 \mathrm{~N} 1, \mathrm{pH} 1 \mathrm{~N} 1, \mathrm{H} 3 \mathrm{~N} 2, \mathrm{H} 5 \mathrm{~N} 1, \mathrm{H} 7 \mathrm{~N}$, and possibly novel IAV strains. Furthermore, the findings highlight the potential of inducing inter-strain cross-protection by the inclusion of a single peptide variant in a $\mathrm{CD} 8^{+} \mathrm{T}$ cell-mediated vaccine, suggesting that vaccine epitope identification will no longer need to focus solely on conserved epitopes for universal inter-strain cross-protection.

Diverse and cross-reactive TCR repertoires are important for viral control and preventing viral escape 27,29 , and we thus dissected the importance of TCR $\alpha \beta$ diversity in the recognition of the variant $\mathrm{NP}_{338}$ peptides. Our data show that cross-recognition of distinct IAV strains is underpinned by a diverse TCR repertoire and surprisingly that no shared clonotypes could be detected between individuals. This highlights that cross-reactivity and TCR $\alpha \beta$ repertoire diversity may provide further protection against distinct IAV strains. Furthermore, TCR $\alpha \beta$ diversity is likely to aid in limiting viral escape, offering protection against any quasispecies that arise during infection. Additionally, we have shown that cross-reactivity towards distinct IAV strains is not limited to HLA-B37-NP 338 , and cross-reactive TCRs towards the HLA-A1-restricted $\mathrm{NP}_{44}$ were also observed. In both contexts, we have isolated cross-reactive clonotypes that were not shared between individuals, showing the plasticity of the TCR repertoire whereby multiple TCRs are able to cross-react and provide protection against multiple IAV strains.

Overall, our study provides evidence that inter-epitope crossreactivity is common for the human influenza epitopes and occurs for prominent HLA-B37-restricted $\mathrm{NP}_{338}$ and HLA-A1restricted $\mathrm{NP}_{44}$ epitopes, in addition to previously published HLA-A ${ }^{\star} 02: 01$-restricted $\mathrm{M}_{58}{ }^{30}$. $\mathrm{CD}^{+} \mathrm{T}$ cells can recognize variations within $\mathrm{CD}^{+} \mathrm{T}$ cell epitopes and cross-reactive $\mathrm{CD} 8^{+}$ TCR $\alpha \beta$ repertoires can recognize variant HLA-B37-restricted $\mathrm{NP}_{338}$ and HLA-A1-restricted $\mathrm{NP}_{44}$ peptides across donors. Together, these data highlight the importance of $\mathrm{CD}^{+} \mathrm{T}$ cell cross-reactivity and diversity in the protection against distinct IAV strains and the induction of such diverse and cross-reactive $\mathrm{CD}^{+} \mathrm{T}$ cells by a CD8 ${ }^{+} \mathrm{T}$ cell-mediated vaccine could provide universal and superior protection against distinct IAV strains.

\section{Methods}

Ethics statement. All work was undertaken in line with the Australian National Health and Medical Research Council (NHMRC) Code of Practice, with ethics approval by the University of Melbourne Human Ethics Committee, ethics numbers 0931311 and 1443389. Australian Red Cross Blood donors provided written informed consent on the day of their blood donation. Written informed consent was obtained from all healthy blood donors. Donor information including HLA typing result is reported in Supplementary Table 3.

$\mathbf{N P}_{\mathbf{3 3 8}}$ conservation analysis. Full-length vaccine, Australian, $\mathrm{pH} 1 \mathrm{~N} 1, \mathrm{H} 5 \mathrm{~N} 1$, and H7N9 isolates with identical sequences collapsed were obtained from the NCBI Influenza Research Database https://www.ncbi.nlm.nih.gov/genomes/FLU/ Database/nph-select.cgi?go=database in February 2018. Sequences were aligned using https://www.fludb.org/brc/home.spg?decorator=influenza.

Antigen-presenting cell lines (APC lines). APC lines were kindly provided by Professor James McCluskey (University of Melbourne, VIC, Australia; C1R $B^{\star} 44: 03$ ) and Dr. Nicole Mifsud (Monash University, VIC, Australia; C1R$\mathrm{B}^{\star}$ 18:01). The A2-20091204 (HLA-B*37:01+) BLCL cells were provided by Professor Weisan Chen (LaTrobe University, VIC, Australia).

Isolation of PBMCs. Buffy coats were obtained from the Australian Red Cross Blood Service (ARCBS) and whole blood donations from healthy volunteers. PBMCs were separated using density gradient separation and were cryopreserved until use. All samples were HLA-typed by the Victorian Transplant and Immunogenetics Service (VTIS, West Melbourne, VIC, Australia) at the ARCBS tissuetyping Laboratory.

Generation of $\mathbf{N P}_{\mathbf{3 3 8}}$-specific $\mathbf{C D 8}{ }^{+} \mathbf{T}$ cell lines. PBMCs were used to generate $\mathrm{CD}^{+} \mathrm{T}$ cell lines at a 1:2 stimulator-to-responder ratio. Stimulator PBMCs were washed in fetal calf serum (FCS)-free media and were pulsed with $10 \mu \mathrm{M}$ (unless otherwise stated) peptide for $90 \mathrm{~min}$ at $37^{\circ} \mathrm{C}$ with $5 \% \mathrm{CO}_{2}$. Stimulator PBMCs were washed twice and added to the responder PBMCs. Cells were cultured for 10-16 days and supplemented twice weekly with $10 \mathrm{U} / \mathrm{mL}$ rIL-2 (Roche, Basel, Switzerland) from day 4.

Intracellular cytokine staining. APC lines expressing HLA-B ${ }^{\star} 37: 01$, HLA-B ${ }^{\star}$ 18:01 or HLA-B ${ }^{\star} 44: 03$ were pulsed with $10 \mu \mathrm{M}$ peptide (unless otherwise stated) in FCS free media for $1 \mathrm{~h}$ at $37^{\circ} \mathrm{C}$ with $5 \% \mathrm{CO}_{2}$. APCs were subsequently washed twice and added to $\mathrm{CD}^{+} \mathrm{T}$ cell lines at 1:2 APC-to-T cell ratio. Alternatively, CD8 ${ }^{+} \mathrm{T}$ cell lines from HLA-B ${ }^{\star} 44: 02^{+}$donors were stimulated directly with $1 \mu \mathrm{M}$ peptide without APCs. Cells were co-cultured for $5-6 \mathrm{~h}$ in the presence of $10 \mathrm{U} / \mathrm{mL}$ IL-2, 5 $\mu \mathrm{M}$ Monensin A (Sigma Aldrich, MO, USA) and Golgi-Stop (BD eBiosciences, CA, USA) with aCD107a-FITC/AF488 (1:100-1:200; eBiosciences \# 53-1079-41, CA, USA) for $5 \mathrm{~h}$. Following activation, cells were surface stained for $30 \mathrm{~min}$ with aCD3-PE (1:25-1:50; BD Pharmingen \# 555333, CA, USA), aCD8-APC

(1:50-1:100; BD Biosciences \# 340584, CA, USA) with or without Live/Dead-NIR (1:1000; Molecular Probes Cat\#L10119, MA, USA), or aCD3-Pey7 (1:50-1:100; eBiosciences \# 25-0038-42), aCD8-PerCPCy5.5 (1:50; BD Biosciences \# 341051) and Live/Dead-NIR (1:1000; Molecular Probes \#L10119). Cells were then fixed with $1 \%$ paraformaldehyde (PFA; Electron Microscopy Sciences, PA, USA) or BDFix-Perm buffer (BD Biosciences) for 15-20 min. Cells were intracellularly stained for $30 \mathrm{~min}$ or overnight with anti-IFN $\gamma$-PerCPCy5.5 (1:100; eBiosciences \#45-7319. 41) and anti-TNFa-PeCy7 (1:100; BD Pharmingen \#557647, CA, USA), anti-IFN $\gamma$ PE (1:40; BD Biosciences \#340452) and anti-TNFa-APC (1:50-1:100; BD Biosciences \#340534) or anti-IFN $\gamma$-V500 (1:50-1:100; BD Horizon \#561980, NY, USA) and anti-TNFa-APC (1:50-1:100; BD Biosciences \#340534) in perm wash buffer (BD Biosciences), or $0.3 \%$ Saponin (Sigma, MO, USA), respectively. Cells were washed, acquired on the BD FACS Canto II (BD Biosciences) and analyzed using the Flowjo software version 9.7.6 (Treestar, OR, USA).

Tetramer staining of $\mathbf{C D 8}{ }^{+} \mathbf{T}$ cell lines. $\mathrm{CD}^{+} \mathrm{T}$ cells were stained with tetramers for $1 \mathrm{~h}$ at room temperature in the dark. Cells were washed and surface stained for $30 \mathrm{~min}$ with aCD3-PeCy7 (1:50-1:100; eBiosciences \#25-0038-42) or aCD3-PB (1:50-1:100; Biolegend \#300431, SD, USA) with aCD8-PerCPCy5 5 (1:50; BD Biosciences \#341051), aCD27-APC (1:50-1:100; BD Biosciences \#337169), aCD45RA-FITC (1:50-1:100; BD Pharmingen \#555488) and Live/Dead- 
NIR (1:1000; Molecular Probes \#L10119) at $4{ }^{\circ} \mathrm{C}$, then either fixed with $1 \%$ PFA (Electron Microscopy Sciences), and acquired on the BD FACS Canto II (BD Biosciences) or resuspended in sort buffer and single-cell sorted on the BD Aria III (BD Biosciences).

Ex vivo magnetic enrichment of PBMCs. In all, $1-2 \times 10^{7}$ PBMCs from HLA$\mathrm{B}^{*} 37: 01^{+}$donors were $\mathrm{FCR}$ blocked in MACS buffer (phosphate-buffered saline (PBS), $0.5 \%$ bovine serum albumin (BSA); Gibco, CA, USA, $0.2 \mathrm{nM}$ EDTA; Ajax Finechem, NSW, Australia) for $15 \mathrm{~min}$ at $4{ }^{\circ} \mathrm{C}$ (Miltenyi Biotech, Bergisch Gladbach, Germany) and tetramer stained with variant-specific tetramers conjugated to $\mathrm{PE}$ in MACS buffer for $1 \mathrm{~h}$ at room temperature. Cells were washed, a small amount was removed for unenriched control, and labeled with anti-PE microbeads (Miltenyi Biotech, Bergisch Gladbach, Germany) for $30 \mathrm{~min}$ at $4{ }^{\circ} \mathrm{C}$. Following washing, cells were enriched by passing twice over LS magnetic columns (Miltenyi Biotech, Bergisch Gladbach, Germany) ${ }^{30,55}$. Bound cells were eluted in MACS buffer. All samples (unenriched, enriched, and flow-through) were surface stained for 30 min with aCD3-PeCy7 (eBiosciences), aCD8-PerCPCy5.5 (BD Biosciences), Live/Dead-NIR (Molecular Probes), aCD14-APCH7 (BD Pharmingen), $\alpha \mathrm{CD} 4$ APCH7 (BD Biosciences), aCD19-APCH7 (Biolegend), aCD27-APC (BD Biosciences) and aCD45RA-FITC (BD Pharmingen) at $4{ }^{\circ} \mathrm{C}$ in the dark. Lymphocytes were washed, re-suspended in sort buffer (PBS, $0.1 \%$ BSA; Gibco, CA, USA), and were acquired on the BD Aria III.

Single-cell multiplex RT-PCR for TCR $\boldsymbol{\alpha} \beta$ analysis. Epitope-specific $\mathrm{CD} 8^{+} \mathrm{T}$ cells from PBMCs or $\mathrm{CD}^{+} \mathrm{T}$ cell lines were tetramer and antibody stained, as described above. Following surface staining, cells were re-suspended in sort buffer (PBS $+0.1 \% \mathrm{BSA}$ ). Single epitope-specific $\mathrm{CD}^{+} \mathrm{T}$ cells were sorted on the BD FACS Aria III (BD Biosciences) directly into PCR plates (Eppendorf, Hamburg, Germany). cDNA was synthesized using the VILO RT Kit at 1/20 of the manufacturer's

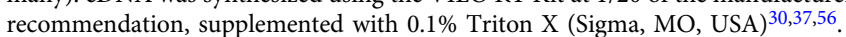
The resulting cDNA was subject to a nested PCR containing $40-\mathrm{V} \alpha$ and $27-\mathrm{V} \beta$ primers and $C \alpha$ and $C \beta$ primers (Supplementary Table 9). PCR products were purified using Exo-Sap or Exo-Star (GE Healthcare, Buckinghamshire, UK) and were sequenced using BigDyeV3.1 (Applied Biosystems, CA, USA). Sequencing products were cleaned using DyeEx sequencing plates (Qiagen, Limburg, Netherlands) and sequencing was performed by the Department of Pathology at the University of Melbourne (Melbourne, VIC, Australia). Sequences were analyzed using Finch TV (Geospiza, WA, USA) and the IMGT query software ${ }^{57,58}$ (www. imgt.org/IMGT_vquest). CDR3 amino acid sequences described within the text are productive (no stop codons and an in-frame junction) TCR $\alpha \beta$ pairs and start from CDR3-position 1, as determined by the IMGT query software. CDR3 length is calculated from position 4 and excludes the final $\mathrm{xF}$ motifs. TRAV and TRBV nomenclature was derived from IMGT www.imgt.org/IMGTrepertoire/ LocusGenes/\#J.

$\mathrm{NP}_{338}{ }^{+} \mathrm{CD} 8{ }^{+} \mathrm{T}$ cells with two alpha or beta chains were dissected by performing the internal round of PCR with the specific individual primers and subsequently sequenced using the relevant constant reverse primer or variablespecific primers (Supplementary Table 9). Where possible, both chains were resolved; however, in a few instances only the dominant chain could be resolved. TRBV $19^{+}$TCR $\beta$ s were sequenced with the TRBV19 forward primer (and are thus referred to as TRBV19) and CDR3 regions were determined using the EXPASY translate tool.

In cases when $\mathrm{NP}_{338}{ }^{+} \mathrm{CD} 8^{+} \mathrm{TCR} \alpha$ or TCR $\beta$ chains could not be resolved, sequences (two cells per clonotype) were resolved by cloning and colony PCR. PCR products were ligated into a pGEM-T Easy Vector (Promega, WI, USA) overnight at $16^{\circ} \mathrm{C}$. DH5 $\alpha$ cells were then transformed with this vector and were grown, plated on Luria agar plates (containing $100 \mu \mathrm{g} / \mathrm{mL}$ ampicillin, Media Preparation Unit, Department of Microbiology and Immunology, University of Melbourne, VIC, Australia) for $16-18 \mathrm{~h}$, and were selected using X-gal ( $800 \mu \mathrm{g})$. Individual transformed colonies were amplified by PCR with 20 pmol sense and anti-sense vector primers (Supplementary Table 9). PCR were amplified as follows: 1 cycle of $95^{\circ} \mathrm{C}$ for $5 \mathrm{~min}, 30$ cycles of $95^{\circ} \mathrm{C}$ for $30 \mathrm{~s}, 57^{\circ} \mathrm{C}$ for $30 \mathrm{~s}$, and $72^{\circ} \mathrm{C}$ for $1 \mathrm{~min}$, followed by 1 cycle of $95^{\circ} \mathrm{C}$ for $1 \mathrm{~min}, 57^{\circ} \mathrm{C}$ for $1 \mathrm{~min}$, and $72^{\circ} \mathrm{C}$ for $7 \mathrm{~min}$. Products were visualized on a $2 \%$ agarose gel and were sequenced as above with 5 pmol of sense vector primer (Supplementary Table 9).

Protein expression, purification, and crystallization. The EM2 TCR contained an engineered disulfide linkage in the constant domains between the TRAC and TRBC. The $\alpha$ - and $\beta$-chains were expressed separately as inclusion bodies in a BL21 Escherichia coli strain. The inclusion bodies were washed and suspended in $6 \mathrm{M}$ guanidine, then mixed into a cold refolding solution containing $5 \mathrm{M}$ urea, $100 \mathrm{mM}$ Tris-HCL ( $\mathrm{pH}$ 8), $2 \mathrm{mM}$ EDTA, $400 \mathrm{mM}$ L-arginine-HCl, $0.5 \mathrm{mM}$ oxidized glutathione, and $5 \mathrm{mM}$ reduced glutathione. The refolding solution was dialyzed after 3 days against $10 \mathrm{mM}$ Tris- $\mathrm{HCl}(\mathrm{pH} 8)$ and $150 \mathrm{mM} \mathrm{NaCl}$ and then purified using anion exchange and size exclusion columns ${ }^{59}$. All peptides were purchased from Genescript (NJ, USA). HLA-B*37:01+-restricted peptides include WT-NP ${ }_{338-346}$ (FEDLRVLSF), L7S-NP ${ }_{338-346}$ (FEDLRVSSF), and V6L-NP ${ }_{338-346}$ (FEDLRLLSF). Soluble class I heterodimers (with or without BirA tag at the C-terminal) of HLA$\mathrm{B}^{\star}$ 18:01 and HLA-B*44:05 containing the $\mathrm{NP}_{338}$ peptides and HLA-B*37:01 containing the $\mathrm{NP}_{338}$ and variant $\mathrm{NP}_{338}$ - $\mathrm{L} 7 \mathrm{~S}$ and $\mathrm{NP}_{338}$-V6L peptides were prepared similarly to the TCR without urea in the refolding solution ${ }^{59}$. Crystals of the EM2 TCR-HLA-B*37:01- $\mathrm{NP}_{338}$ complex or the pHLA individually in $10 \mathrm{mM}$ Tris$\mathrm{HCl}(\mathrm{pH} 8.0)$ and $150 \mathrm{mM} \mathrm{NaCl}$ were grown by the hanging-drop, vapor-diffusion method at $20^{\circ} \mathrm{C}$ with a protein to reservoir drop ratio of $1: 1$ and a protein concentration of $6-10 \mathrm{mg} / \mathrm{mL}$. The pHLA crystals formed in $20 \%$ PEG 6000, $0.2 \mathrm{M}$ $\mathrm{NaCl}, 0.1 \mathrm{M} \mathrm{Na}$ citrate $\mathrm{pH} 6.5$ while the EM2 TCR-HLA-B ${ }^{*} 37: 01-\mathrm{NP}_{338}$ complex crystals formed in 19\% PEG 3350 and $0.2 \mathrm{M}$ di-ammonium tartrate. Monomers of pHLA with the BirA tag construct were biotinylated and tetramerized in a 1:4 ratio with PE-streptavidin (Life Technologies, CA, USA) in 6 additions over the course of $1 \mathrm{~h}$.

Data collection and structure determination. Crystals were soaked in a cryoprotectant solution containing mother liquor solution with the PEG concentration increased to $30 \%$ (weight per volume) and then flash frozen in liquid nitrogen. Data were collected on the MX1 beamline at the Australian Synchrotron, Clayton using the ADSC-Quantum $210 \mathrm{CCD}$ detector $(\text { at } 100 \mathrm{~K})^{60}$. Data were processed using the XDS software ${ }^{61}$ and scaled using the XSCALE software ${ }^{61}$. The pHLA and EM2 TCR-HLA-B ${ }^{*} 37: 01-\mathrm{NP}_{338}$ complex structures were determined by molecular replacement using the PHASER ${ }^{62}$ program with the HLA- $\mathrm{A}^{\star} 02: 01-\mathrm{NLV}$ complex as the search model for the HLA without the peptide (Protein Data Bank accession number, $3 \mathrm{GSO}^{59}$ ) and the LC13 TCR for the TCR (Protein Data Bank accession number, $1 \mathrm{KGC}^{63}$ ). Manual model building was conducted using the Coot software $^{64}$ followed by maximum-likelihood refinement with PHENIX ${ }^{65}$ and Buster programs ${ }^{66}$. The TCR was numbered using the IMGT nomenclature ${ }^{57}$. The final models have been validated using the Protein Data Base validation website and the final refinement statistics are summarized in Supplementary table 2. Coordinates were validated by the PDB database. All molecular graphic representations were created using $\mathrm{PyMol}^{67}$.

Thermal stability assay. The thermal stability assay was performed in the Real Time Detection system (Corbett RotorGene 3000) using the fluorescent dye Sypro orange to monitor protein unfolding. The pHLA complexes (5 and $10 \mu \mathrm{M})$ in 10 $\mathrm{mM}$ Tris- $\mathrm{HCl} \mathrm{pH} 8$ and $150 \mathrm{mM} \mathrm{NaCl}$ were heated from 30 to $95^{\circ} \mathrm{C}$ with a heating rate of $1{ }^{\circ} \mathrm{C} / \mathrm{min}$. The fluorescence intensity was measured with excitation at 530 $\mathrm{nm}$ and emission at $555 \mathrm{~nm}$. The thermal melt point $(\mathrm{Tm})$ represents the temperature for which $50 \%$ of the protein is unfolded.

Surface plasmon resonance measurement and analysis. Surface plasmon resonance experiments were conducted at $25^{\circ} \mathrm{C}$ on the BIAcore 3000 instrument with TBS buffer $(10 \mathrm{mM}$ Tris- $\mathrm{HCl}$, pH $8,150 \mathrm{mM} \mathrm{NaCl}$, and $0.005 \%$ surfactant P20). TBS buffer was supplemented with $1 \%$ BSA to prevent non-specific binding. The human TCR-specific monoclonal antibody, $12 \mathrm{H} 8$ antibody ${ }^{68}$, was coupled to research-grade CM5 chips with standard amine coupling. The experiment was conducted with one empty flow cell (use for subtraction as blank) and one flow cell with the EM2 TCR captured to approximately 300 response unit per flow cell onto the $12 \mathrm{H} 8$ antibody ${ }^{68}$. Then a concentration range of $200 \mu \mathrm{M}$ maximum of the pHLA complexes were passed over all the flow cells. The final response was calculated by subtracting the response of the antibody alone and that of EM2 TCR. BIAevaluation Version 3.1 was used for data analysis using the 1:1 Langmuir binding model. Experiments were carried out in duplicate $(n=2)$.

Statistical analyses. All statistical analyses were undertaken using Prism 6 (GraphPad, CA, USA). A Dunnett's two-way analysis of variance was used for all non-parametric non-paired analysis where multiple comparisons were made. Statistical significance was defined as ${ }^{*} p \leq 0.05,{ }^{* *} p \leq 0.01$, and ${ }^{* * *} p \leq 0.001$.

\section{Data availability}

Coordinates submitted to PDB database, and the PDB codes are 6MT6 (HLA$\mathrm{B}^{\star} 37: 01-\mathrm{NP}_{338}$ ), 6MT4 (HLA-B $\left.37: 01-\mathrm{NP}_{338}-\mathrm{L} 7 \mathrm{~S}\right), 6 \mathrm{MT} 5$ (HLA-B ${ }^{*} 37: 01-\mathrm{NP}_{338}$ V6L), 6MTL (HLA-B*44:05-NP ${ }_{338}$ ), 6MT3 (HLA- ${ }^{*} 18: 01-\mathrm{NP}_{338}$ ), and 6MTM (EM2 TCR-HLA-B*37:01-NP 338 ). All other data that support the findings of this study are available from the corresponding author upon reasonable request. A reporting summary for this article is available as a Supplementary Information file.

Received: 24 July 2018 Accepted: 23 November 2018 Published online: 21 December 2018

\section{References}

1. Grant, E. J., Quinones-Parra, S. M., Clemens, E. B. \& Kedzierska, K. Human influenza viruses and CD8(+) T cell responses. Curr. Opin. Virol. 16, 132-142 (2016).

2. Krammer, F. et al. Influenza. Nat. Rev. Dis. Prim. 4, 3 (2018).

3. WHO. http://www.who.int/mediacentre/factsheets/fs211/en/ (2015). 
4. Ahmed, R., Oldstone, M. B. \& Palese, P. Protective immunity and susceptibility to infectious diseases: lessons from the 1918 influenza pandemic. Nat. Immunol. 8, 1188-1193 (2007).

5. Koutsakos, M. et al. Circulating TFH cells, serological memory, and tissue compartmentalization shape human influenza-specific B cell immunity. Sci. Transl. Med. https://doi.org/10.1126/scitranslmed.aan8405 (2018).

6. McKinstry, K. K., Dutton, R. W., Swain, S. L. \& Strutt, T. M. Memory CD4 T cell-mediated immunity against influenza A virus: more than a little helpful. Arch. Immunol. Ther. Exp. 61, 341-353 (2013).

7. Kilbourne, E. D. et al. The total influenza vaccine failure of 1947 revisited: major intrasubtypic antigenic change can explain failure of vaccine in a postWorld War II epidemic. Proc. Natl. Acad. Sci. USA 99, 10748-10752 (2002).

8. Wells, M. A., Albrecht, P. \& Ennis, F. A. Recovery from a viral respiratory infection. I. Influenza pneumonia in normal and T-deficient mice. J. Immunol. 126, 1036-1041 (1981).

9. Bender, B. S., Croghan, T., Zhang, L. \& Small, P. A. Jr. Transgenic mice lacking class I major histocompatibility complex-restricted $\mathrm{T}$ cells have delayed viral clearance and increased mortality after influenza virus challenge. J. Exp. Med. 175, 1143-1145 (1992).

10. Laidlaw, B. J. et al. Cooperativity between CD8+ T cells, non-neutralizing antibodies, and alveolar macrophages is important for heterosubtypic influenza virus immunity. PLoS Pathog. 9, e1003207 (2013).

11. Valkenburg, S. A. et al. Protective efficacy of cross-reactive CD8+ T cells recognising mutant viral epitopes depends on peptide-MHC-I structural interactions and T cell activation threshold. PLoS Pathog. 6, e1001039 (2010).

12. Quinones-Parra, S. M. et al. A role of influenza virus exposure history in determining pandemic susceptibility and CD8+ T cell responses. J. Virol. 90, 6936-6947 (2016)

13. Valkenburg, S. A. et al. Acute emergence and reversion of influenza A virus quasispecies within CD8+ T cell antigenic peptides. Nat. Commun. 4, 2663 (2013).

14. Bird, N. L. et al. Oseltamivir prophylaxis reduces inflammation and facilitates establishment of cross-strain protective $\mathrm{T}$ cell memory to influenza viruses. PLoS ONE 10, e0129768 (2015).

15. Valkenburg, S. A. et al. Early priming minimizes the age-related immune compromise of CD8(+) T cell diversity and function. PLoS Pathog. 8, e1002544 (2012)

16. McMichael, A. J., Gotch, F. M., Noble, G. R. \& Beare, P. A. Cytotoxic T-cell immunity to influenza. N. Engl. J. Med. 309, 13-17 (1983).

17. Sridhar, S. et al. Cellular immune correlates of protection against symptomatic pandemic influenza. Nat. Med. 19, 1305-1312 (2013).

18. Wang, Z. et al. Recovery from severe H7N9 disease is associated with diverse response mechanisms dominated by CD8(+) T cells. Nat. Commun. 6, 6833 (2015).

19. Wang, Z. et al. Clonally diverse CD38(+)HLA-DR(+)CD8(+) T cells persist during fatal H7N9 disease. Nat. Commun. 9, 824 (2018).

20. Hillaire, M. L. et al. Human T-cells directed to seasonal influenza A virus cross-react with 2009 pandemic influenza A (H1N1) and swine-origin triplereassortant H3N2 influenza viruses. J. Gen. Virol. 94, 583-592 (2013).

21. Tu, W. et al. Cytotoxic T lymphocytes established by seasonal human influenza cross-react against 2009 pandemic H1N1 influenza virus. J. Virol. 84, 6527-6535 (2010).

22. Gras, S. et al. Cross-reactive CD8+ T-cell immunity between the pandemic H1N1-2009 and H1N1-1918 influenza A viruses. Proc. Natl. Acad. Sci. USA 107, 12599-12604 (2010).

23. Quinones-Parra, S. et al. Preexisting CD8+ T-cell immunity to the H7N9 influenza A virus varies across ethnicities. Proc. Natl. Acad. Sci. USA 111 1049-1054 (2014).

24. Lee, L. Y. et al. Memory T cells established by seasonal human influenza A infection cross-react with avian influenza A (H5N1) in healthy individuals. $J$. Clin. Invest. 118, 3478-3490 (2008).

25. Kreijtz, J. H. et al. Cross-recognition of avian H5N1 influenza virus by human cytotoxic T lymphocyte populations directed to human influenza A virus. J. Virol. 82, 5161-5166 (2008).

26. van de Sandt, C. E. et al. Human cytotoxic T lymphocytes directed to seasonal influenza A viruses cross-react with the newly emerging H7N9 virus. J. Virol. 88, 1684-1693 (2014).

27. Messaoudi, I., Guevara Patino, J. A., Dyall, R., LeMaoult, J. \& Nikolich-Zugich, J. Direct link between mhc polymorphism, T cell avidity, and diversity in immune defense. Science 298, 1797-1800 (2002).

28. Valkenburg, S. A. et al. Fixing an irrelevant TCR alpha chain reveals the importance of TCR beta diversity for optimal TCR alpha beta pairing and function of virus-specific CD8+ T cells. Eur. J. Immunol. 40, 2470-2481 (2010).

29. Ladell, $\mathrm{K}$. et al. A molecular basis for the control of preimmune escape variants by HIV-specific CD8 + T cells. Immunity 38, 425-436 (2013).

30. Valkenburg, S. A. et al. Molecular basis for universal HLA-A ${ }^{\star} 0201$-restricted CD8+ T-cell immunity against influenza viruses. Proc. Natl. Acad. Sci. USA 113, 4440-4445 (2016).
31. Ganusov, V. V. et al. Fitness costs and diversity of the cytotoxic T lymphocyte (CTL) response determine the rate of CTL escape during acute and chronic phases of HIV infection. J. Virol. 85, 10518-10528 (2011).

32. Meyer-Olson, D. et al. Limited T cell receptor diversity of HCV-specific T cell responses is associated with CTL escape. J. Exp. Med. 200, 307-319 (2004).

33. Wooldridge, L. et al. A single autoimmune $\mathrm{T}$ cell receptor recognizes more than a million different peptides. J. Biol. Chem. 287, 1168-1177 (2012).

34. Boon, A. C. et al. Recognition of homo- and heterosubtypic variants of influenza A viruses by human CD8+ T lymphocytes. J. Immunol. 172, 2453-2460 (2004).

35. Wahl, A. et al. T-cell tolerance for variability in an HLA class I-presented influenza A virus epitope. J. Virol. 83, 9206-9214 (2009).

36. Cole, D. K. et al. Hotspot autoimmune T cell receptor binding underlies pathogen and insulin peptide cross-reactivity. J. Clin. Invest. 126, 2191-2204 (2016).

37. Wang, G. C., Dash, P., McCullers, J. A., Doherty, P. C. \& Thomas, P. G. T cell receptor alphabeta diversity inversely correlates with pathogen-specific antibody levels in human cytomegalovirus infection. Sci. Transl. Med. 4, $128 \mathrm{ra1} 42$ (2012).

38. Nguyen, T. H. et al. Recognition of distinct cross-reactive virus-specific CD8+ $\mathrm{T}$ cells reveals a unique TCR signature in a clinical setting. J. Immunol. 192, 5039-5049 (2014)

39. Grant, E. et al. Nucleoprotein of influenza A virus is a major target of immunodominant CD8+ T-cell responses. Immunol. Cell Biol. 91, 184-194 (2013).

40. DiBrino, M. et al. HLA-A1 and HLA-A3 T cell epitopes derived from influenza virus proteins predicted from peptide binding motifs. J. Immunol. 151, 5930-5935 (1993).

41. DiBrino, M. et al. Identification of the peptide binding motif for HLA-B44, one of the most common HLA-B alleles in the Caucasian population. Biochemistry 34, 10130-10138 (1995).

42. Rammensee, H., Bachmann, J., Emmerich, N. P., Bachor, O. A. \& Stevanovic, S. SYFPEITHI: database for MHC ligands and peptide motifs. Immunogenetics 50, 213-219 (1999).

43. Macdonald, W. et al. Identification of a dominant self-ligand bound to three HLA B44 alleles and the preliminary crystallographic analysis of recombinant forms of each complex. FEBS Lett. 527, 27-32 (2002).

44. Macdonald, W. A. et al. A naturally selected dimorphism within the HLA-B44 supertype alters class I structure, peptide repertoire, and T cell recognition. J. Exp. Med. 198, 679-691 (2003).

45. Macdonald, W. A. et al. T cell allorecognition via molecular mimicry. Immunity 31, 897-908 (2009).

46. Rist, M. J. et al. HLA peptide length preferences control CD8+ T cell responses. J. Immunol. 191, 561-571 (2013).

47. Archbold, J. K. et al. Natural micropolymorphism in human leukocyte antigens provides a basis for genetic control of antigen recognition. J. Exp. Med. 206, 209-219 (2009).

48. Rist, M. J. et al. T cell cross-reactivity between a highly immunogenic EBV epitope and a self-peptide naturally presented by HLA-B ${ }^{\star} 18: 01+$ cells. J. Immunol. 194, 4668-4675 (2015).

49. McCluskey, J. et al. in The HLA Complex in Biology and Medicine: A Resource Book 1st edn (ed. Mehra, N. K.) Ch. 6 (Jaypee Brothers Medical Publishers, New Delhi, 2010).

50. Rossjohn, J. et al. T cell antigen receptor recognition of antigen-presenting molecules. Annu. Rev. Immunol. 33, 169-200 (2015).

51. Wu, C. et al. Systematic identification of immunodominant CD8+ T-cell responses to influenza A virus in HLA-A2 individuals. Proc. Natl. Acad. Sci. USA 108, 9178-9183 (2011)

52. Archbold, J. K. et al. Alloreactivity between disparate cognate and allogeneic pMHC-I complexes is the result of highly focused, peptide-dependent structural mimicry. J. Biol. Chem. 281, 34324-34332 (2006).

53. Birnbaum, M. E. et al. Deconstructing the peptide-MHC specificity of T cell recognition. Cell 157, 1073-1087 (2014).

54. Stadinski, B. D. et al. Hydrophobic CDR3 residues promote the development of self-reactive T cells. Nat. Immunol. 17, 946-955 (2016).

55. Nguyen, T. H. et al. Understanding CD8 $(+)$ T-cell responses toward the native and alternate HLA-A*02:01-restricted WT1 epitope. Clin. Transl. Immunol. 6, e134 (2017).

56. Grant, E. J. et al. Lack of heterologous cross-reactivity toward HLA-A*02:01 restricted viral epitopes is underpinned by distinct alphabeta $\mathrm{T}$ cell receptor signatures. J. Biol. Chem. 291, 24335-24351 (2016).

57. Brochet, X., Lefranc, M. P. \& Giudicelli, V. IMGT/V-QUEST: the highly customized and integrated system for IG and TR standardized V-J and V-D-J sequence analysis. Nucleic Acids Res. 36, W503-W508 (2008).

58. Giudicelli, V., Brochet, X. \& Lefranc, M. P. IMGT/V-QUEST: IMGT standardized analysis of the immunoglobulin (IG) and T cell receptor (TR) nucleotide sequences. Cold Spring Harb. Protoc. 2011, 695-715 (2011). 
59. Gras, S. et al. Structural bases for the affinity-driven selection of a public TCR against a dominant human cytomegalovirus epitope. J. Immunol. 183, 430-437 (2009).

60. Cowieson, N. P. et al. MX1: a bending-magnet crystallography beamline serving both chemical and macromolecular crystallography communities at the Australian Synchrotron. J. Synchrotron Radiat. 22, 187-190 (2015).

61. Kabsch, W. XDS. Acta Crystallogr. D Biol. Crystallogr. 66, 125-132 (2010).

62. Read, R. J. Pushing the boundaries of molecular replacement with maximum likelihood. Acta Crystallogr. D Biol. Crystallogr. 57, 1373-1382 (2001).

63. Kjer-Nielsen, L. et al. The 1.5 A crystal structure of a highly selected antiviral $\mathrm{T}$ cell receptor provides evidence for a structural basis of immunodominance. Structure 10, 1521-1532 (2002).

64. Emsley, P. \& Cowtan, K. Coot: model-building tools for molecular graphics. Acta Crystallogr. D Biol. Crystallogr. 60, 2126-2132 (2004).

65. Adams, P. D. et al. PHENIX: a comprehensive Python-based system for macromolecular structure solution. Acta Crystallogr. D Biol. Crystallogr. 66, (213-221 (2010).

66. Smart, O. S. et al. Exploiting structure similarity in refinement: automated NCS and target-structure restraints in BUSTER. Acta Crystallogr. D Biol. Crystallogr. 68, 368-380 (2012).

67. DeLano, W. L. The PyMOL Molecular Graphics System (DeLano Scientific, 2002).

68. Gras, $\mathrm{S}$. et al. The shaping of $\mathrm{T}$ cell receptor recognition by self-tolerance. Immunity 30, 193-203 (2009).

\section{Acknowledgements}

We thank Hanim Halim, the Monash Macromolecular Crystallization Facility staff and the staff at the Australian synchrotron for technical assistance. This work was supported by Australian National Health and Medical Research Council (NHMRC) Project (AI1008854) and Program (AI1071916) Grants awarded to K.K. E.J.G. is supported by an Early Career NHMRC CJ Martin Fellowship; J.R. by an Australian Research Council (ARC) Laureate fellowship; S.G. is a Monash Senior Research Fellow; and K.K. is supported by an NHMRC SRF Level B Fellowship.

\section{Author contributions}

Conceived and designed the experiments: E.J.G., K.K., S.G., M.B., W.C. Performed the experiments: E.J.G., E.B.C., L.L., S.G. Analyzed the data: E.J.G., T.J., L.L., S.S., E.B.C., S.G. Wrote the paper: E.J.G., T.J., M.B., J.R., W.C., K.K., S.G.

\section{Additional information}

Supplementary Information accompanies this paper at https://doi.org/10.1038/s41467018-07815-5.

Competing interests: The authors declare no competing interests.

Reprints and permission information is available online at http://npg.nature.com/ reprintsandpermissions/

Publisher's note: Springer Nature remains neutral with regard to jurisdictional claims in published maps and institutional affiliations.

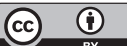

Open Access This article is licensed under a Creative Commons Attribution 4.0 International License, which permits use, sharing, adaptation, distribution and reproduction in any medium or format, as long as you give appropriate credit to the original author(s) and the source, provide a link to the Creative Commons license, and indicate if changes were made. The images or other third party material in this article are included in the article's Creative Commons license, unless indicated otherwise in a credit line to the material. If material is not included in the article's Creative Commons license and your intended use is not permitted by statutory regulation or exceeds the permitted use, you will need to obtain permission directly from the copyright holder. To view a copy of this license, visit http://creativecommons.org/ licenses/by/4.0/

(C) The Author(s) 2018 